\title{
Recent Perspectives in Ocular Drug Delivery
}

\author{
Ripal Gaudana, ${ }^{1}$ J. Jwala, ${ }^{1}$ Sai H. S. Boddu, ${ }^{1}$ and Ashim K. Mitra ${ }^{1,2}$
}

Received May 11, 2008; accepted July 22, 2008; published online August 29, 2008

\begin{abstract}
$\overline{\text { Abstract. Anatomy and physiology of the eye makes it a highly protected organ. Designing an effective }}$ therapy for ocular diseases, especially for the posterior segment, has been considered as a formidable task. Limitations of topical and intravitreal route of administration have challenged scientists to find alternative mode of administration like periocular routes. Transporter targeted drug delivery has generated a great deal of interest in the field because of its potential to overcome many barriers associated with current therapy. Application of nanotechnology has been very promising in the treatment of a gamut of diseases. In this review, we have briefly discussed several ocular drug delivery systems such as microemulsions, nanosuspensions, nanoparticles, liposomes, niosomes, dendrimers, implants, and hydrogels. Potential for ocular gene therapy has also been described in this article. In near future, a great deal of attention will be paid to develop non-invasive sustained drug release for both anterior and posterior segment eye disorders. A better understanding of nature of ocular diseases, barriers and factors affecting in vivo performance, would greatly drive the development of new delivery systems. Current momentum in the invention of new drug delivery systems hold a promise towards much improved therapies for the treatment of vision threatening disorders.
\end{abstract}

KEY WORDS: nanotechnology; ocular drug delivery; transporter.

\section{INTRODUCTION}

Ocular drug delivery has remained as one of the most challenging task for pharmaceutical scientists. The unique structure of the eye restricts the entry of drug molecules at the required site of action. Drug delivery to the eye can be broadly classified into anterior and posterior segments (Fig. 1). Conventional systems like eye drops, suspensions and ointments cannot be considered optimal in the treatment of vision threatening ocular diseases (1). However, more than $90 \%$ of the marketed ophthalmic formulations are in the form of eye drops. These formulations mainly target the anterior segment eye diseases (2). Most of the topically applied drugs are washed off from the eye by various mechanisms (lacrimation, tear dilution and tear turnover) resulting in low ocular bioavailability of drugs. Moreover, human cornea comprising of epithelium, substantia propria and endothelium also restricts the ocular entry of drug molecules (3). As a result of these factors less than $5 \%$ of administered drug enters the eye. Alternative approaches like incorporation of permeation enhancers/cyclodextrins and increasing the viscosity of solutions did not provide any significant improvement. Recently many drug efflux pumps have been identified and significant enhancement in ocular drug absorption was

\footnotetext{
All the authors contributed equally to this work.
${ }^{1}$ Division of Pharmaceutical Sciences, School of Pharmacy, Univer- sity of Missouri-Kansas City, 5005 Rockhill Road, Kansas City, Missouri 64110-2499, USA.

${ }^{2}$ To whom correspondence should be addressed. (e-mail: mitraa@ umkc.edu)
}

achieved following their inhibition or evasion. But prolonged use of such inhibitors may result in undesirable effects (4).

Treatment of posterior segment diseases still remains a herculean task for the formulation scientists. The tight junctions of blood retinal barrier (BRB) restrict the entry of systemically administered drugs into the retina (5). High vitreal drug concentrations are required in the treatment of posterior segment diseases. This can be made possible only with the local administration (intravitreal injections/implants and periocular injections). Periocular injections are associated with fairly high patient compliance as compared to intravitreal injections (6).

Dramatic changes have been observed in the field of ocular drug delivery over a decade. Insight into various membrane transporters/receptors present on the eye opened a new window of opportunities. Especially polar drug molecules, which fail to permeate ocular barriers, can be conveniently delivered via transporter/receptor targeted drug delivery systems (7). This review article briefly covers pathology of various ocular diseases and their current therapies. We have also given emphasis on the role of various ocular transporters and recent developments in drug delivery strategies including gene therapy. We have briefly discussed ocular deliver systems, gene therapy, and recent developments like microneedle and iontophoresis

\section{OVERVIEW ON ANATOMY AND DISEASES AFFECTING EYE}

Broadly we discuss the structure of eye under two subheadings (a) anterior segment and (b) posterior segment. 
Anterior segment consists of front one-third of eye that mainly includes pupil, cornea, iris, ciliary body, aqueous humor, and lens while the posterior segment consists of the back two-thirds of the eye that includes vitreous humor, retina, choroid, macula, and optic nerve (Fig. 1) $(8,9)$. In this article we made an attempt to briefly discuss the major diseases affecting the eye. These include age-related macular degeneration (AMD), diabetic macular edema (DME), cataract, proliferative vitreoretinopathy (PVR), uveitis, cytomegalovirus (CMV), and glaucoma. Table I highlights the classification, signs and symptoms and current treatment options for these diseases.

\section{DELIVERY ROUTES}

Conventionally, many ocular diseases are treated with either topical or systemic medications. Topical application of drug has remained the most preferred method due to ease of administration and low cost. Topical application is useful in the treatment of disorders affecting the anterior segment of the eye (10). Anatomical and physiological barriers hinder drugs from reaching posterior segment of eye mainly at choroid and retina. A major fraction of drug following topical administration is lost by lacrimation, tear dilution, nasolacrimal drainage and tear turnover. Such precorneal losses result in very low ocular bioavailability. Typically, less than $5 \%$ of the total administered dose reaches aqueous humor (11). So, in order to maintain minimum inhibitory concentrations, the agents need to be frequently dosed resulting in poor patient compliance. Upon topical instillation drugs are absorbed either by corneal route (cornea $\rightarrow$ aqueous humor $\rightarrow$ intraocular tissues) or non-corneal route (conjunctiva $\rightarrow$ sclera $\rightarrow$ choroid/RPE). The preferred route depends mainly on the corneal permeability of drug molecules (12). Unlike topical administration, systemic dosing helps in the treatment of diseases affecting posterior segment of the eye. A major drawback associated with systemic administration is only 1$2 \%$ of administered drug reaches to vitreous cavity. Blood retinal barrier which is selectively permeable to more lipophilic molecules mainly governs the entry of drug molecules into posterior segment of the eye. This results in frequent administration of high amounts of drugs leading to systemic side effects (13). Though topical and systemic routes are convenient, lack of adequate bioavailability and failure to deliver therapeutic amounts of drugs to the retina prompted the vision scientists to search for alternative routes of administration.

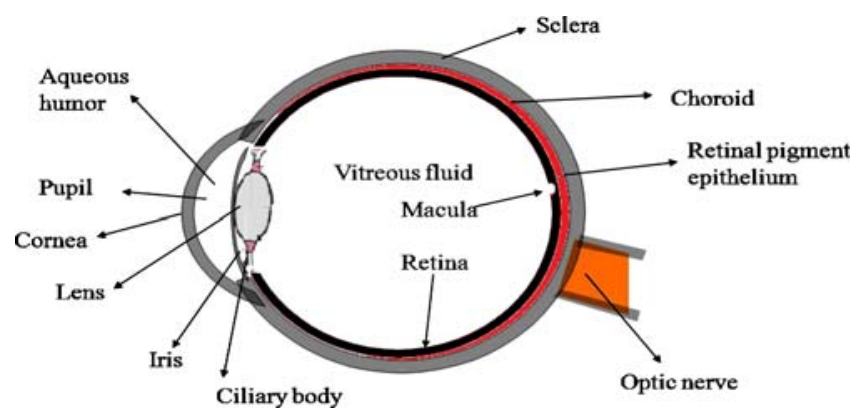

Fig. 1. Structure of eye.
Intravitreal injections have gained considerable momentum during the past two decades. This method involves injection of drug solution directly into vitreous via pars plana using a $30 \mathrm{G}$ needle. Unlike other routes, intravitreal injection offers higher drug concentrations in vitreous and retina. Elimination of drugs following intravitreal administration depends on their molecular weight. Linear and globular shaped molecules (especially protein and peptide drugs) with molecular weight greater than 40 and $70 \mathrm{kDa}$ respectively tend to cause longer retention in vitreous humor (14).

Though intravitreal administration offers high concentrations of drugs in retina, it is associated with various short term complications such as retinal detachment, endophthalmitis and intravitreal hemorrhages (15). Moreover, patients need to be carefully monitored following intravitreal injections.

Periocular route has been considered as the most promising and efficient route for administering drugs to posterior eye segment. Periocular refers to the region surrounding the eye. It is a broad term which includes peribulbar, posterior juxtascleral, retrobulbar, subtenon and subconjunctival routes (Fig. 2). Drug solutions are placed in close proximity to the sclera which results in high retinal and vitreal concentrations. Sclera which is made up of fibrous tissue offers less resistance to permeability of drugs (16). Ghate et al., studied the pharmacokinetics of sodium fluorescein following periocular administration in rabbits. The study concluded that administration of drug via subtenon injection resulted in the highest and sustained vitreous concentration of sodium fluorescein compared to retrobulbar and subconjunctival routes (17). Anterior segment complications have been observed in some patients following periocular injections. These include rise in intraocular pressure, cataract, hyphema, strabismus and corneal decompensation (18).

\section{NUTRIENT TRANSPORTERS AND EFFLUX PUMPS IN THE EYE}

Epithelial cells express various nutrient transporters and receptors on their membrane surface. These nutrient transporters aid in the movement of various vitamins and amino acids across the cell membrane. Our laboratory has extensively studied various transporters and receptors which are present on ocular structures. We have also shown that attachment of various transporters/receptors targeted ligands enhances ocular bioavailability significantly. A detailed discussion of all influx transporters is beyond the scope of this review. So, we have mentioned some the important ones.

\section{PEPTIDE TRANSPORTER}

It is a fairly robust transporter which has gained considerable attention in recent years for targeted drug delivery (19). These proton coupled transporters help in the translocation of di and tripeptides across the epithelium (20). These proteins are mainly classified into PepT1, PepT2 and peptide/histidine transporters (PHT 1 and PHT 2). Many drug molecules are known to be substrates for these transporters. Our laboratory has shown the presence of an oligopeptide transporter on rabbit cornea (21). Other drugs including $\beta$-lactam antibiotics, renin inhibitors and ACEinhibitors are known to be substrates for PepT1 and PepT2. 


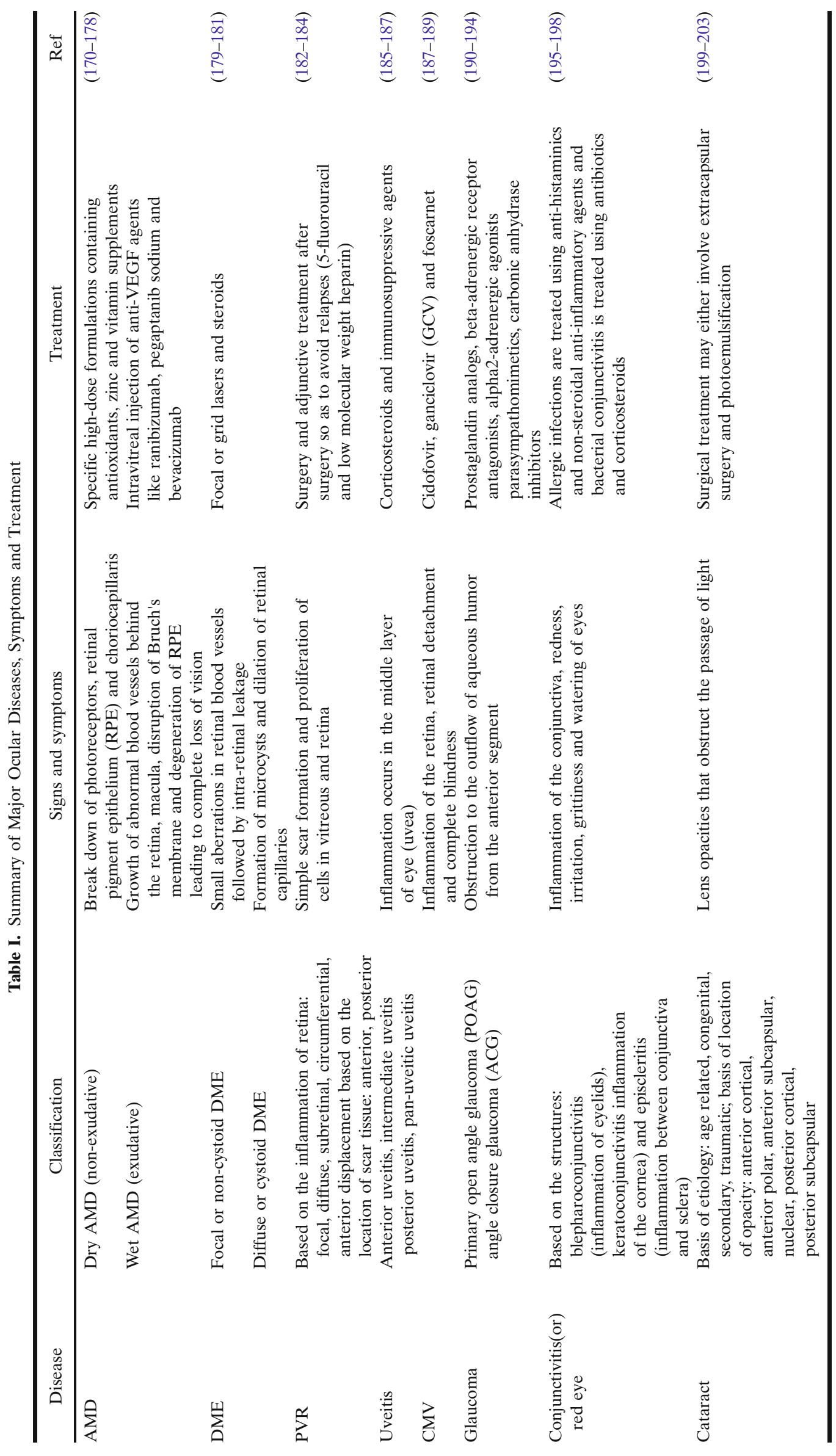




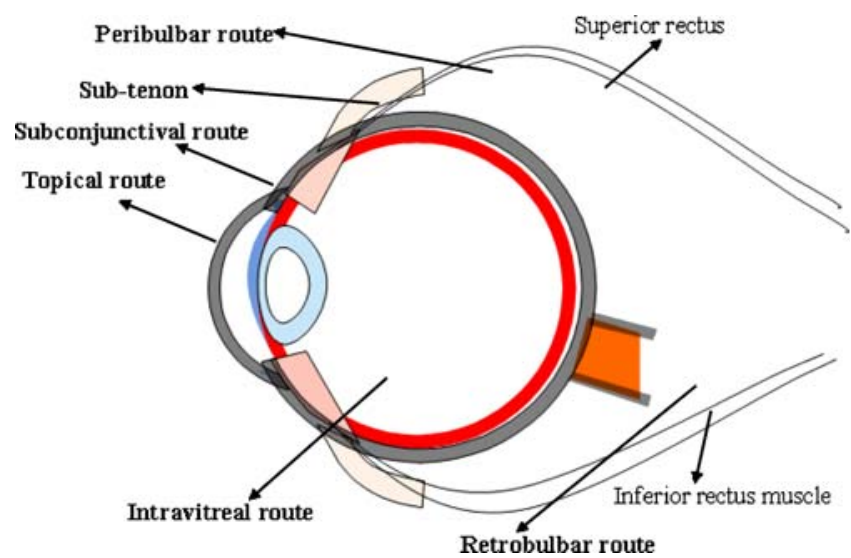

Fig. 2. Routes of ocular drug delivery.

Ocheltree et al., demonstrated the expression of PHT1 in BRPE, HRPE (human RPE cells), ARPE-19 (human RPE cell line), and bovine and human neural retina. However, they could find the expression PEPT2 and PHT2 only in bovine and human retina; and PEPT1was not detected. They also concluded that glycylsarcosine uptake studies did not demonstrate any significant functional activity of PHT1 on plasma membranes of RPE (22). We have also investigated the mechanism of model dipeptide (glycylsarcosine) transport across the blood-ocular barriers following systemic administration in our laboratory. A time and concentration dependent, carrier mediated uptake of glycylsarcosine across the blood-ocular barrier was reported (23). Prodrugs (valine$\mathrm{ACV}$ and valine-valine-ACV) exhibited higher concentrations of $\mathrm{ACV}$ in aqueous humor following systemic administration as compared to parent drug. This study indicates that peptide prodrugs are taken up via carrier mediated transport mechanism (24). Hence, drugs with poor ocular bioavailability can be suitably modified so that they can be recognized by peptide transporters.

\section{GLUCOSE TRANSPORTER}

Glucose is utilized by the retina to meet the energy need of oxidative metabolism. Neural retina is considered to have the highest metabolic rate per unit weight (25). So, an alteration in the metabolic rate can lead to potential ocular complications. Glucose is transported across the blood-retinal and blood aqueous barriers by a stereo-specific, saturable process of facilitated diffusion. Glucose transporters are expressed in various isoforms GLUT1, GLUT2, GLUT3, GLUT4, GLUT5, GLUT6 and GLUT7. Out of these GLU1, GLU3, and GLU4 are high-affinity glucose transporters where as GLUT5 is a high-affinity fructose transporter. GLUT2 is considered to be low affinity glucose transporter. GLUT6 is a pseudogene which does not encode for a functional transporter. GLUT7 is similar to GLUT2 but only expressed in endoplasmic reticulum (26). Mantych et al., studied the presence of various isoforms of glucose transporter (Glut 1, Glut 3, Glut 4, and Glut 5) in human eye using western blot and immunohistochemical techniques. This study reported presence of Glut 1 in RPE, choroid, pars plana, retinal Mueller cells, and lens fiber cells (27). Glucose transporters are more efficient and have more capacity than any other nutrient transporter. But high substrate specificity of glucose transporters renders them inefficient for drug delivery purpose.

\section{VITAMIN C TRANSPORTER}

Vitamin $\mathrm{C}$ or ascorbic acid (AA) acts as an antioxidant and thereby protects the cornea and other ocular tissues from $\mathrm{UV}$ radiations. Aqueous humor is the main source of AA for cornea and lens. AA levels in aqueous humor are partly responsible for preventing cataract (28). Two specific transporters (SVCT-1 and SVCT-2) of vitamin C were identified in the ocular tissues of human, rabbit and rat. These transporters have identical sequence homology. Transport of AA across the cells is mediated by two different transporter families. One consists of the low affinity and high capacity facilitative hexose transporters (GLUT) which translocate dehydro ascorbic acid (oxidized form of ascorbic acid), and the other consists of high affinity and low capacity sodium dependent vitamin C transporters (SVCT1 and SVCT2) that ferries L-ascorbic acid (reduced form of ascorbic acid) (29).

\section{AMINO ACID TRANSPORTER}

Amino acids are responsible for protein synthesis and maintenance of structural and functional integrity of conjunctiva and retina/RPE. These transporters help in transferring amino acids from circulating blood to various organs. The presence of various amino acid transporters (ASCT1, LAT1 and $\mathrm{ATB}^{0+}$ ) on the cornea has been confirmed by gene expression. These transporters are actively involved in the transportation of $\mathrm{L}$-alanine, $\mathrm{L}$ arginine and $\mathrm{L}$-phenylalanine across the cornea. Amino acid transporters can be classified on the basis of their sodium dependency and substrate specificity (30). System L (large) and system y+ (cationic) amino acid transporters belong to sodium independent transporters while system $\mathrm{X}$ - (anionic), system $\mathrm{A}, \mathrm{B}^{0,+}$, ASC (anionic, cationic, and neutral amino acid transporters) belong to sodium dependent transporter category (21). Large neutral amino acid transporter is expressed in two isoforms LAT1 and LAT2. LAT1 is mainly involved in the transport of large neutral amino acids, such as Leu, Phe, Ile, Trp, Val, Tyr, His and Met while LAT2 transports both large neutral amino acids and small neutral amino acids $(31,32)$. Transport systems for amino acids have been characterized on corneal epithelium and endothelium. Gandhi et al., studied the biochemical evidence of sodium independent facilitative transport system, LAT2, with high substrate specificity on ARPE-19 cell line (33). Blisse et al., reported the presence of sodium-dependent, $\mathrm{B}^{0,+}$ amino acid transporter with broad substrate specificity on rabbit corneal epithelium and human cornea. This transporter belongs to neurotransmitter gene family and found to have affinity comparable to PEPT1 in the transport of prodrugs, like valine-ACV and valine-GCV $(34,35)$. Such transport systems may be efficiently targeted for enhancing ocular delivery of drugs.

\section{EFFLUX TRANSPORTERS}

Efflux of various substrates across plasma membrane and cytoplasm into extracellular fluid is mainly governed by $\mathrm{ABC}$ 
(ATP-binding cassette) superfamily of proteins which are encoded by MDR1 gene (36). ABC transporters are broadly classified into two types (a) complete transporter, contains four units (two nucleotide-binding domains and two membrane bound domains) and (b) half transporter, which possesses only two units (one nucleotide-binding domain and one membrane-bound domain). Half transporter must attach with another half transporter to perform its action (37). These ABC proteins are actively involved in detoxification process by regulating the transport of various sterols, lipids, endogenous metabolic products and xenobiotics (38). Literature search reveals that mainly two multidrug efflux pumps are responsible for the development of chemoresistance (a) $\mathrm{P}$-glycoprotein $(\mathrm{ABCB} 1)$ and $(\mathrm{b})$ multidrug resistant protein (MRP) (ABCC1) (39).

$\mathrm{P}-\mathrm{gp}$ is a $170 \mathrm{kDa}$ membrane bound efflux protein generally expressed on the apical surface of polarized cells (40). P-glycoprotein is actively involved in the efflux of drug molecules thereby reducing drug accumulation inside cells (41). The presence of P-gp in the eye has been confirmed on conjunctival epithelial cells (42), ciliary non-pigmented epithelium (43), human and rabbit cornea (44), retinal capillary endothelial cells, iris and ciliary muscle cells (45). Constable et al., studied the presence of P-gp on three human RPE cell lines, ARPE19, D407 and h1RPE. They concluded that only D407 cell functionally express P-gp and hence can be used for in vitro drug transport studies without any modifications (46).

MRP is a $190 \mathrm{kDa}$ membrane bound efflux protein encoded by MRP1 gene. It is generally expressed on the basolateral surface of intestine, hepatocytes and kidney cells $(47,48)$. Till now 12 different members of MRP family have been studied (49). MRP's are actively involved in the effluxing glucuronide, sulfate conjugated compounds and organic anions. Aukunuru et al., studied the presence of functionally and biochemically active MRP on human RPE cell line (50). Further studies by Steuer et al., confirmed that MRP is present on the choroidal side of the outer blood retinal barrier (51). Recently, studies from our laboratory revealed the presence of ABCC2 (a MRP homologue) on human corneal epithelium and rabbit cornea (52). Recently Zhang et al., have performed an extensive research on implications of drug transporter and CYP P450 mRNA Expression in ocular drug disposition. They concluded that both BCRP and MRP2 have very low expression levels in the human cornea while there were moderate MRP1 and low MRP3 expression levels in the human cornea. Moreover, designing drugs that can efficiently evade MRP1 efflux may play an important role in enhancement of ocular penetration (53).

Efflux pumps constitute significant barriers to the entry of drug molecules. It is indeed necessary to develop alternative strategies which can improve ocular drug absorption.

\section{PRODRUG APPROACH TO ENHANCE OCULAR BIOAVAILABILITY}

Prodrug strategy has been attempted for improving therapeutic efficacy of many drug molecules. Significant advantages in various properties like solubility, stability, permeability and evasion of efflux pump have been gained.
Shirasaki has recently reviewed various molecular approaches to enhance drug permeation across the cornea (54). Our laboratory has also aggressively pursued the exploitation of many of these transporters for ocular drug absorption. Amino acid and peptide prodrugs of acyclovir (ACV) and ganciclovir (GCV), targeting various amino acid and peptide transporters have been developed and evaluated in our laboratory. Dipeptide (glycine-valine and tyrosine-valine) monoester prodrugs of GCV were found to show superior corneal absorption and bioavailability compared to parent drug (55). These attempts are highly effective in treating herpes simplex virus-1 (HSV-1) induced corneal epithelial and stromal keratitis (56). Permeability values of valine-GCV, tyrosinevaline-GCV, and glycine-valine-GCV were found to be higher than parent GCV which was attributed to their interaction with oligopeptide transporter present on the retina (57). Sustained release microsphere formulations of GCV and its lipophilic prodrug GCV-monobutyrate, with higher entrapment efficiency, were developed using PLGA in our laboratory (58). By using a similar strategy, L-valyl ester of acyclovir (ACV) was also developed and found to be more permeable across rabbit cornea due to its interaction with the oligopeptide transporter (24). Ocular penetration of peptide prodrug of ACV (valine-valine-ACV), was higher than the parent drug following systemic administration in rabbits. The prodrugs appear to be less cytotoxic, highly water-soluble with excellent in vivo activity against HSV-1 in rabbit epithelial and stromal keratitis (59). Our laboratory has also demonstrated that prodrug derivatization can effectively circumvent P-gp mediated efflux of quinidine across rabbit cornea (60).

TG100801, which converts to TG100572 by de-esterification, was found to be effective in the treatment of ocular neovascularization and retinal edema following topical administration (61). Due to this prodrug approach, incidence of systemic toxicity was found to be greatly diminished. Role of phase I and phase II ocular metabolic activities was also reviewed recently to rationalize design of prodrug and codrug for ocular delivery by Crooks et al., (62). UNIL088, a water-soluble prodrug of cyclosporine A was developed via an ester linkage which gets converted into parent drug by chemical or enzymatic hydrolysis of the terminal ester group (63). Cannabinoids usually lowers IOP by their interaction with the ocular cannabinoid receptors. The solubility related problem of cannabinoids was solved by making arachidonylethanolamide, $R$-methanandamide, noladin ether and their water-soluble phosphate ester prodrugs (64). This modification has resulted in higher corneal permeation which could result in more efficient reduction in IOP. In another study, combretastatin A-4-phosphate (CA-4-P), a water soluble prodrug of combretastatin A-4 (CA-4), was found to suppress the development of VEGF-induced neovascularization in the retina and also block development of CNV (65). Topical formulation of nepafenac was found to effectively penetrate into the corneal tissue which also reaches into the posterior segment. In animal models it was found to inhibit CNV and ischemia-induced retinal neovascularization. Nepafenac is converted to amfenac which has significant higher permeability across the cornea. This property is primarily responsible for appearance of the nepafenac to the posterior segment and causing inhibition of VEGF (66). 


\section{NOVEL OCULAR DRUG DELIVERY SYSTEMS}

Colloidal carriers have been widely exploited in the field of drug delivery science. It provides a more selective targeting along with sustained release of molecules at the desired site. Applications of nanotechnology can be very exciting in the treatment of a gamut of diseases affecting the anterior as well as the posterior segment of the eye. One has to understand the physiological and biochemical factors involved in normal and pathological conditions for designing a successful ocular drug delivery system.

An ideal therapy requires selectively targeting of active agent to various diseases like $\mathrm{CNV}$, diabetic retinopathy and solid tumors in the eye. Retina does not possess lymphatic system moreover angiogenesis in this part of eye has similar features to the solid tumor with enhanced permeability and retention (EPR) effects $(67,251)$. Delivery of a drug via nanotechnology based product fulfills mainly three objectives as follows (1) enhances drug permeation (2) controls the release of drug (3) targets drug (251). Main focus was given to colloidal systems consisting of micro/nanoparticles, micro/ nanoemulsions, nanosuspensions and liposomes. In the last decade, dendrimers, niosomes, and cyclodextrins have also been exploited to achieve optimal drug delivery. Ocular implants have also been emerged as an alternative to the conventional delivery systems. The role of iontophoresis and ultrasound has also gained momentum in ocular delivery. Encapsulation of drugs in these colloidal carriers can also significantly enhance permeation across the membrane and prevent degradation from the ocular enzymes $(68,69)$. Such biodegradable carriers can be developed as an alternative to the implant prepared from nonbiodegradable polymers, which has to be removed surgically after a certain period. Sometimes the surgical process can cause complications like astigmatism, vitreous hemorrhage and patient incompliance.

\section{MICROEMULSIONS}

Microemulsions are dispersions of water and oil facilitated by a combination of surfactant and co-surfactant in a manner to reduce interfacial tension. These systems are usually characterized by higher thermodynamic stability, small droplet size $(\sim 100 \mathrm{~nm})$ and clear appearance (70). A review on application of microemulsions in ocular drug delivery by Vandamme et al., deals systematically with the various developments and challenges happening in the field. Selection of aqueous phase, organic phase and surfactant/cosurfactant systems are critical parameters which can affect stability of the system. Optimization of these components results in significant improvement in solubility of the drug molecule e.g. indomethacin, chloramphenicol (71). Apart from solubility, microemulsion systems have also been exploited to improve permeation across the cornea. An oilin-water system consisting of pilocarpine using lecithin, propylene glycol, PEG 200 as surfactant/co surfactants, and isopropyl myristate as the oil phase has been designed, which is nonirritating to the rabbit animal model (72). Such formulations often provide sustained drug release thereby reducing frequency of the drug administration. In case of pilocarpine, microemulsion based system lowers the frequency of administration to two times as compared to four times with conventional eye drops in a day. This was due to enhancement of the permeation by surfactant-co-surfactant combination. Another microemulsion system consisting of pilocarpine hydrochloride (73) was shown to convert in different forms like (liquid crystalline and coarse emulsion) with a change in rheological parameters which changed depending upon change in water content. This results in higher viscosity which will retain the formulation on the cornea resulting in its enhanced effect. Timolol in microemulsion system was laden in a 2-hydroxyethyl methacrylate (HEMA) gels which was studied to modulate its transport across the gel (74). The authors have achieved higher drug loading but could not control its release. In another attempt to deliver timolol, a stable $\mathrm{o} / \mathrm{w}$ and w/o emulsion was formulated which met all the requirements of an eye drop according to Polish Pharmacopeia V. Sirolimus, a highly lipophilic drug with aqueous solubility of $2.6 \mu \mathrm{g} / \mathrm{mL}$ was formulated in microemulsion system which could hold $1 \mathrm{mg}$ of drug in the system with excellent stability and tolerability (75). An alcohol free, microemulsion based formulation consisting chloramphenicol was developed. This formulation exhibited excellent stability when compared to commercially available formulation. Though microemulsions have excellent advantages limitations in selection of surfactant/co-surfactant system and potential toxicity associated with higher concentrations of surfactant/co-surfactant often restricts its use (76).

\section{NANOSUSPENSIONS}

This can be defined as sub-micron colloidal system which consists of poorly water-soluble drug, suspended in an appropriate dispersion medium stabilized by surfactants. Nanosuspenisons usually consist of colloidal carriers like polymeric resins which are inert in nature. They help in enhancement of drug solubility and thus bioavailability. Unlike microemulsions, they are also popular because of their non irritant nature. Flurbiprofen encapsulated in eudragit RS $100 \AA$ and RL $100 \AA$ polymer resins prevents myosis, which might be induced during extracapsular cataract surgery (77). Charge on the surface of nanoparticles facilitates its adhesion to the cornea. Methylprednisolone acetate (MPA) was encapsulated in a copolymer of poly (ethylacrylate, methyl-methacrylate and chlorotrimethyl-ammonioethyl methacrylate) and examined for its effect on the anti-inflammatory symptoms in rabbits with endotoxin-induced uveitis (EIU) (78). Animal studies have revealed that anti-inflammatory effect of nanosuspensions was more than microsuspensions. Similar studies were carried out using piroxicam in eudragit $\mathrm{RS} 100$. In vivo studies in rabbits have shown significant anti-inflammatory effects compared to microsuspensions (79). In another approach, three different types of glucocorticoids; hydrocortisone, prednisolone and dexamethasone were formulated as nanosuspensions. In vivo study in rabbits suggested that the nanosuspensions significantly enhanced the ocular absorption of glucocorticoids (80). These nanosuspensions also produce sustained drug release and were more effective over a longer duration. Nanosuspensions also impart stability to the drug in the formulation. Cloricromene (AD6) was formulated in nanosuspensions by using eudragit RS100 and RL100. AD6-loaded eudragit retarded nanoparticle suspension offered a significant edge in 
enhancing the shelf life and bioavailability of the drug following ophthalmic application (81).

\section{NANOPARTICLES}

According to Sahoo et al., "Nanoparticles are defined as particles with a diameter of less than $1 \mu \mathrm{m}$, comprising of various biodegradable or non biodegradable polymers, lipids, phospholipids or metals" (251). They can be classified as nanospheres or nanocapsules depending upon whether the drug has been uniformly dispersed or coated within polymeric material. Recent studies have revealed the migration of intact nanoparticles to the RPE cells following intravitreal injection of nanoparticles suspension $(82,251)$. This migration had been attributed to the rupture of the internal limiting membrane (ILM) and activation of non-specific retinal microglial cells. Such mild transient mechanism in the inflammatory process also modifies permeability and the anchoring mechanism of the ILM. These findings are crucial for the diseases affecting the posterior segment of the eye. Uptake and distribution of nanoparticles depend on the size of the nanoparticles. Kinetics of fluorescein nanospheres (2000, 200 and $50 \mathrm{~nm}$ ) was studied following intravitreal injection in rabbits. Nanospheres smaller than $200 \mathrm{~nm}$ were also observed in the retinal cells other than the vitreous cavity and trabecular meshwork where only larger diameter particles were distributed. This study has shown the importance of particle size in ocular tissue distribution (83). Many formulation parameters have to be considered in designing an ideal formulation. Surface charge interaction of the drug and polymer has played an important role in drug release from the polymer. Incomplete release of progesterone from the polybutyl cyanoacrylate nanospheres was attributed to the surface charge interaction of the drug and polymer (84, 251). A solid lipid nanoparticulate system of tobramycin was developed for topical drug delivery. Such a particulate system can be retained for longer duration on the corneal surface and also on the conjunctival sac compared to an aqueous solution of the drug. In vivo testing has shown sustained drug release over a period of $6 \mathrm{~h}$ compared to short duration from equal dose of eye drops (85). Recently Kompella et al., have evaluated how the ocular disposition and distribution of different size of nanoparticles (20 and $200 \mathrm{~nm}$ ) vary due to blood and lymph circulations following periocular administration in Sprague Dawley rats (86). They found that particles with $20 \mathrm{~nm}$ size were transported across the sclera to a small extent and no significant transport was noted across the sclera-choroid-RPE. Such low permeation was attributed to periocular circulation (blood and lymphatic) which play a crucial role in clearing the $20 \mathrm{~nm}$ particles. A higher concentration of particles in the ocular tissues was observed in dead animals by the post-mortem studies which they concluded because of the lack of physiological barrier following periocular administration. An ideal nanoparticulate formulation should have low clearance by blood and lymphatic circulation in order for it to be effective in the treatment of posterior segment diseases following periocular administration.

Various naturally occurring polymers were studied as carriers for the nanoparticulate system. Albumin nanoparticles can effectively encapsulate both positively (GCV) and negatively charged (oligonucleotides (ODNs)) molecules (87). Chitosan coated poly (epsilon-caprolactone) nanopar- ticles of indomethacin resulted in twofold enhancement in ocular bioavailability (88). Enhanced permeation across the cornea was also observed when poly (epsilon-caprolactone) nanoparticles were coated with polyethylene glycol (89). In another study, a formulation comprising dexamethasone acetate encapsulated in biodegradable PLGA nanoparticles was administered by the intravitreal route and the effect on CNV was studied. This study demonstrated a triphasic pattern of drug release. The drug level was found to be more than the level required to treat CMV (90). In another study, mucoadhesive chitosan-sodium alginate nanoparticles were prepared and evaluated for topical delivery of gatifloxacin. This system resulted in burst release during the first hour followed by sustained release for $24 \mathrm{~h}$. This approach helps in reducing the dosing frequency of the antibiotic because of the sustained action observed after single administration (91).

Moshfeghi et al., have extensively reviewed the perspectives of particulate delivery system (micro and nanoparticles) in ophthalmology (92). Intravitreal administration of red nuclear fluorescent protein entrapped in PLGA has been shown to localize in RPE cells where red nuclear fluorescent protein plasmid expression was also observed (93). Phosphorothioate ODNs were either adsorbed or incorporated in albumin nanoparticles and antiviral efficacy was examined. Nanoparticles having entrapped ODNs were found to exhibit higher antiviral activity than nanoparticles with the adsorbed drug on the surface. This may be due to the protection of ODNs from enzymatic degradation (94). Particulate delivery system of ODNs has resulted in their higher stability, efficacy and reduction in non specific toxicity $(95,96)$. Currently, we are working on the delivery of various steroidal nanoparticles of mean particle diameter $\approx 200 \mathrm{~nm}$ via subconjunctival administration. In our laboratory, we are also working to optimize various in vitro properties of steroidal nanoparticles. These nanoparticles can be suspended in thermosensitive gels for subconjunctival administration. Further attachment of various ligands (folate and biotin) to the surface of these nanoparticles helps in increasing the uptake by RPE cells. This approach can be applied for the treatment of various posterior segment diseases such as wet AMD, PVR and DME.

Microspheres can sustain the release of the ODNs after intravitreal injection for longer time period. As microspheres do not enter the cells, a new approach called "Trojan" delivery system was invented. In this type of delivery system, polymeric microspheres were designed to control release of the nanosized anti-TGF 32 phosphorothioate ODNs complexes. Such "Trojan" delivery was much more efficient for bleb survival following trabeculectomy than the microsphere or control alone (97). Macugen ${ }^{\circledR}$ was also entrapped in microspheres and studied following transscleral delivery. In vitro release study has shown release of macugen $(2 \mu \mathrm{g} /$ day) up to 20 days across the sclera. Inhibition of endothelial cell proliferation confirmed that biological activity was not affected by encapsulation (98).

\section{LIPOSOMES}

Liposomes are lipid vesicles containing aqueous core which have been widely exploited in ocular delivery for various drug molecules. Liposomes containing GCV were formulated by a reversed phase evaporation method and in vivo pharmacokinetic evaluation was performed in a rabbit 
model. Permeability of GCV solution was compared with the liposomal formulation containing GCV. Transcorneal permeability and area under the curve (AUC) were was 3.9 and 1.7 fold higher than the solution. Ocular tissue distribution was higher in the sclera, cornea and vitreous humor from liposomal formulation (99). Vasoactive intestinal peptide (VIP) was formulated in liposomal formulation (VIP-Lip). Concentration of VIP following intravitreal injection was about 15 times higher in ocular fluid than the concentration achieved by administration of VIP solution alone. The peptide was effective only when formulated in liposomal form (100). Ciprofloxacin (CPFX) was also formulated in liposomal environmental which lowered tear-driven dilution in the conjunctival sac. Multilamellar vesicles from lecithin and alpha-L-dipalmithoyl-phosphatidylcholine were used to prepare liposome containing CPFX. This approach produced sustained release of the drug depending on the nature of the lipid composition selected (101). Acetazolamide was encapsulated in liposomal formulation for delivery via topical route. Liposomes were prepared using reversed-phase evaporation (REVs) and multilamellar vesicles (MLVs). Different molar ratios of phosphatidylcholine and cholesterol were added in the preparation of MLVs which resulted in higher entrapment efficiency as compare to REV. Entrapment efficiency ascended with higher amounts of lipid and charge inducers such as cholesterol and stearylamine. In-vivo intraocular pressure was examined for selective formulation and liposomes. MLVs exhibited prolong efficacy than liposomes prepared by REV (102). In another study cationic liposomes containing herpes simplex virus type 1 (HSV-1) glycoprotein $\mathrm{B}$ (gB1s) or, DTK1 and DTK2 (two related polylysine rich peptides) were prepared and examined in the rabbit ocular model of HSV-1 keratitis. These peptides (antigen) in liposomal formulation have the potential to act as very effective anti-HSV vaccine (103). In a similar manner, liposomes of tilisolol were also prepared and studied following topical and intravitreal administrations. Positively charged liposomal formulation of tropicamide and oligolamellar liposomes of ACV were generated. Both formulations resulted in significantly higher absorption across the cornea (104).

Antisense ODNs encapsulated in liposomes have been studied for their potential to treat ocular disorders. Various factors need to be carefully considered before such a system is adopted clinically. In topical delivery, liposome may not be able to release the entire payload of high molecular weight ODNs relative to a free solution form (105). Liposomal formulation can release ODNs in a sustained manner following intravitreal injection (106). PEGylated liposome containing ODNs, results in higher percentage of intact ODNs $(30 \%$ of the total dose) after 2 weeks. Some researchers have formulated liposomes coated with an envelope of inactivated hemagglutinating virus of Japan (HVJ) to treat $\mathrm{CNV}$ in rats. They successfully delivered phosphorothioate ODNs to inhibit VEGF (107).

\section{NIOSOMES}

Niosomes are bilayered structural vesicles made up of non-ionic surfactant which are capable of encapsulating both lipophilic and hydrophilic compounds. In a recent approach to deliver cyclopentolate, niosomal formulation was devel- oped. It released the drug independent of $\mathrm{pH}$ resulting in significant enhancement of ocular bioavailability $(108,251)$. Niosomal formulation of coated (chitosan or carbopol) timolol maleate exhibited significant IOP lowering effect in rabbits as compared to timolol solution. Another novel delivery system known as discomes has been developed. These are large structures with a size range of $12-16 \mu \mathrm{m}$ derived by incorporating nonionic surfactant Solutan C24 in niosomes. A major advantage of this system was less systemic drainage because of the large size and large residence time in the cul-de-sac due to their disc shape. Timolol maleate was successfully entrapped in discomes and niosomes. In vivo bioavailability of the discomes was better than the niosomes $(109,251)$.

\section{DENDRIMERS}

According to Sahoo et al., "Dendrimers are macromolecular compounds made up of a series of branches around a central core. Their nanosize, ease of preparation, functionalization and possibility to attach multiple surface groups render them suitable alternative vehicle for ophthalmic drug delivery" (110, 111, 251). Previously, poly (acrylic) acids were prepared as bioadhesive polymers to achieve better residence time and decrease the frequency of administration. Major drawbacks associated with these systems are blurred vision and formation of a veil leading to vision loss (112). Dendrimers are liquid or semi-solid polymers and contain amine, carboxylic and hydroxyl surface groups, which keep on increasing as the generation number increases (G0, G1, G2, and so on). Dendrimers consisting of poly (amidoamine) (PAMAM) have been widely employed in drug delivery. This system of branched polymers represent unique architecture, and can entrap both hydrophilic and lipophilic drugs into their structure (113-115, 251). Selection of functional group on the surface (amine, carboxylate and hydroxyl), size and molecular weight of the dendrimer are important parameters to be considered in designing a delivery system.

Dendrimer based approach has shown better bioavailability of pilocarpine and tropicamide, when DG1.5 and DG4.0 $(\mathrm{OH})$ dendrimers with carboxylate and hydroxyl surface groups were instilled (116). Some of the researchers have synthesized water soluble conjugates of $\mathrm{D}(+)$-glucosamine and $\mathrm{D}(+)$-glucosamine 6-sulfate to obtain synergistic immunomodulatory and antiangiogenic effect by using anionic PANAM (G3.5) dendrimers (117). The investigators have also shown successful increase in long term surgery after testing the formulation in a rabbit model of scar tissue formation after glaucoma filtration surgery. Cell-adhesion peptides were also attached to dendrimers which were later used to link with collagen scaffolds (118). Stratification of corneal epithelial cell was studied using the above mentioned collagen scaffolds. All peptides have shown promoted effect on stratification. The same investigators have actively developed biocompatible conjugates of dendrimers with collagen scaffolds to obtain better mechanical property and adhesion ability. In another approach, dendrimers based approach was used to deliver antiVEGF ODN and successfully tested in rats to treat CNV (119). Effect of size, molecular weight and number of surface groups (amine, carboxylate and hydroxyl) of PANAM was studied to understand feasibility for its controlled release of pilocarpine nitrate and some tropicamide (116). 


\section{CYCLODEXTRINS}

As per Sahoo et al., "Cyclodextrins (CDs) belong to a group of cyclic oligosaccharides capable of forming inclusion complexes with many guest molecules (120). Through CD complexation, aqueous solubility of hydrophobic drugs can be enhanced without changing their molecular structure and their intrinsic ability to permeate biological membranes (251)". Molecules having low aqueous solubility have been delivered as $\mathrm{CD}$ complexes. These complexes have been proven to increase corneal permeation of drugs like dexamethasone, cyclosporine and so on. CD complexation approach can significantly increase ocular bioavailability of poorly water soluble drugs. In some cases such inclusion complexes can impart aqueous stability to drugs within the formulation as well (121). Recently a study was carried out to determine relative concentration of dexamethasone in CDs following topical and systemic absorption in the rabbit eye. Investigators observed a significant amount of drug reaching to the posterior segment tissue like retina and vitreous humor following topical application of eye drops. Such an approach might be very valuable in the treatment of vitreoretinal diseases which require long term delivery of drug molecules (122). In another study, the researchers have prepared inclusion complex of HP- $\beta-C D$ with zinc diethyldithiocarbamate and disulfiram which resulted in higher corneal permeability and also lower side effects like development of cataract relative to drug alone $(123,124)$. In a similar approach, inclusion complexes were prepared with rhEGF/HP- $\beta-C D$ which were suspended in poloxamer gel. This formulation has resulted in significant increase in AUC of the drug. This approach has an additional advantage of imparting stability to the drug (125). Inclusion complexes of drugs like dexamethasone, dexamethasone acetate and pilocarpine with HP- $\beta-C D$ resulted in higher bioavailability than the conventional eye drops $(126,127)$. This complexation approach does not disrupt the biological membrane compared to conventional permeation enhancer like benzalkonium chloride. Apart from that, due to inclusion, the free drug is not available, so drugs with inherent irritant properties can be successfully delivered by this approach. CD molecules are inert in nature and HP- $\beta$ CD (up to $45 \%$ ) was found to be non irritant to the human and animal eye (120).

\section{CONTACT LENSES}

Liewen et al., reported an extensive study on polymeric hydrogels for contact lens-based ocular drug delivery (128). Traditionally used soaked contact lenses provide a drug release for a few hours. Current challenges in this mode of drug delivery are to sustain release for longer period and also to incorporate sufficient drug amounts in the lens matrix. Recently, surfactant loaded (Brij 98) poly-hydroxy ethyl methacrylate ( $p$-HEMA) gel has shown sustained release of cyclosporine-A (129). In a similar approach, dexamethasone, dexamethasone 21-disodium phosphate and dexamethasone 21-acetate were suspended in $p$-HEMA based gel to achieve controlled release (130). The bioavailability of the formulation was found to be better than the topical eye drops. In a different kind of approach, two different kind of silicone and hydrogel lens were compared for 1 month. The silicon based lens was shown to be more beneficial to the patient with hypoxia but also found to form more lipid deposit compared to the other. The same investigators have prepared silicon based hydrogel using different ratios to sustain the release of the timolol, dexamethasone, and dexamethasone 21-acetate over the time of several weeks to 3 months (131). The different ratios of monomers could be changed depending upon the delivery required. The prepared lenses were also studied for its mechanical and physical properties. The residence time of a system could be lengthened by suspending nanoparticulate based drugs in thermogelling polymers. The contact lens, containing a nanoparticulate based drug, is an attractive alternative to the topical drug delivery, especially eye drops $(3,132)$. A major benefit of this strategy is to prolong residence time in post tear film which in case of topical drops is just a few minutes. Due to increased residence time in eye, drug permeation through the cornea is higher with specific delivery of the drug to targeted tissue. In another study, drug molecule entrapped in a nanoparticulate system was later dispersed in lens made up of poly-2hydroxyethyl methacrylate ( $p$-HEMA) hydrogels. This approach provide controlled drug release over a few days and delivery rate could be further modulated by changing loading dose of the particles in the gel (133).

\section{INTRAOCULAR IMPLANTS}

Implants have been widely employed to extend the release in ocular fluids and tissues particularly in the posterior segment. Implants can be broadly classified into two categories based on their degradation property (1) biodegradable and (2) non-biodegradable. With implants, the delivery rate could be modulated by varying polymer composition. Implants can be in the form of solid, semi-solid or particulate based delivery systems (134). These implants have been applied in the treatment of diseases affecting both anterior and posterior segments of the eye. The diseases include anterior segment disorders like glaucoma filtering surgery and posterior segment disorders like proliferative vitroretinopathy, CMV retinitis, endophthalmitis, and posterior capsule opacification. Table II summarizes the recent strategies of formulating an implant for various ocular pathologies.

Drug release from Poly lactic acid (PLA), poly glycolic acid (PGA) and poly lactic-co-glycolic acid (PLGA) usually follows three phases of drug release which constitute an initial burst, a middle diffusive phase and a final burst of the drug. In recent years, much attention has been paid to manipulate release profiles to achieve longer duration of release from the implants $(135,136)$. In one study, two PLA monomers of different molecular weight were used in different ratios and, a pseudo-zero order release was obtained with minimum burst effect (137). Recently, co-polymerization of caprolactone with poly-glycolide-co-lactide lead to the development of glycolide-co-lactide-co-caprolactone copolymer (PGLC) which was successfully applied to treat corneal allograft and uveitis (138, 139). Polyanhydrides have also been utilized for these indications (140). Polyorthoesters (POE) are hydrophobic in nature and usually degrade by surface erosion thus providing zero order release kinetics. Among the four generations, third generation POE forms gel like matrix at room temperature. Fourth generation POEs have gained much attention cur- 
Table II. Implants for the Treatment of Ocular Pathologies

\begin{tabular}{|c|c|c|c|}
\hline Drug & Polymer & Characteristic/treatment & Ref \\
\hline Episcleral implant of betamethasone & PVA- EVA & Zero order release up to 4 weeks & $(204)$ \\
\hline Triamcinolone acetonide (TA) & PVA & Controls $\mathrm{CNV}$ in a rat model & (205) \\
\hline Dexamethasone scleral implant (Surodex ${ }^{\circledR}$ ) & PLGA & After phacotrabeculectomy surgery & (206) \\
\hline Intracameral implant of cyclosporine & PLGA & $\begin{array}{l}\text { Prevents corneal graft rejection or } \\
\text { post-operative inflammation in rats }\end{array}$ & $(207)$ \\
\hline 5-Fluorouracil (5-FU) & POE & $\begin{array}{l}\text { Less toxicity and persistence bleb } \\
\text { for longer time }\end{array}$ & $(208)$ \\
\hline $\begin{array}{l}\text { Combination of drug 5-fluorouridine, TA and } \\
\text { recombinant tissue plasminogen activator }\end{array}$ & PLGA & $\begin{array}{l}\text { Treatment of PVR after intravitreal } \\
\text { injection }\end{array}$ & $(209)$ \\
\hline Cis-4-hydroxyproline & PLGA 65/35 + PLGA 50/50 & Treatment of PVR & $(210)$ \\
\hline Subretinal implant of sirolimus and TA & $\begin{array}{l}\text { Poly butylmethacrylate, poly } \\
\text { ethylene-co-vinyl acetate }\end{array}$ & Treatment of ocular inflammation & $(211)$ \\
\hline Intravitreal implant of fluocinolone acetonide & PVA & $\begin{array}{l}\text { Controlled release for more than } \\
1 \text { year to treat severe uveitis }\end{array}$ & $(212)$ \\
\hline FK506 & PGLC & $\begin{array}{l}\text { Prolongation of corneal allograft } \\
\text { survival }\end{array}$ & $(139)$ \\
\hline Cyclosporine A & PGLC & Treatment of uveitis & $(138)$ \\
\hline Intracameral implant of dexamethasone & & Corneal graft rejection & (213) \\
\hline Scleral implants of GCV & PLA & CMV retinitis & (137) \\
\hline Scleral implant of Ethacrynic acid (ECA) & PLGA films & To reduce IOP for 10 days & $(214)$ \\
\hline Cyclosporin A (Oculex Drug Delivery System) & PLGA & $\begin{array}{l}\text { Prophylaxis and treatment of corneal } \\
\text { transplant rejection in humans }\end{array}$ & $(215)$ \\
\hline Dexamethasone & PLGA & $\begin{array}{l}\text { Anterior segment drug delivery system } \\
\text { in patients after phacoemulsification }\end{array}$ & $(216)$ \\
\hline Intracapsular ring releasing 5 -FU & - & $\begin{array}{l}\text { Preventing posterior capsule opacification } \\
(\mathrm{PCO}) \text { in rabbit eyes }\end{array}$ & $(217)$ \\
\hline Heparin & PLGA & $\begin{array}{l}\text { Posterior capsular opacification (PCO) } \\
\text { in rabbits }\end{array}$ & $(218)$ \\
\hline
\end{tabular}

$P V A-E V A$ Polyvinyl alcohol-ethylene vinyl acetate, $P V A$ polyvinyl alcohol, $P G L C$ ploy glycolide-co-clatide-co-caprolactone polymer, $P L G A$ poly latide-co-glycolide-acid, $P L A$ poly lactic acid, $P O E$ poly ortho esters

rently because of their slow erosion property due to the presence of latent acid in the polymer backbone (141).

Recently, researchers have also focused on intravitreal injection of implant using cell encapsulation technology. FGF2 implant embedded in AN69 copolymer delayed photoreceptor degeneration (142). Various synthetic polymers like polyether sulfone, caprolactone and polyvinylpyrrolidone were developed and then positioned with a titanium anchor in the vitreous cavity (143). In a similar study, ciliary neurotrophic factor (CNTF) was released from cells implanted without any side effects for several weeks. A dose dependent protective effect on photoreceptors was noticed with CNTF in rabbits (144). A novel device ECT NT-501 was developed to support the implanted cells (145). After loading CNTF secreting cells in the device, a controlled release of protein was observed for 1 year in the rabbit eye. In a clinical trial, this device appeared to protect photoreceptors in several patients (146).

\section{HYDROGEL SYSTEMS}

These are three-dimensional, hydrophilic, polymeric networks capable of imbibing large amounts of water or biological fluids. Nanjawade et al., have extensively reviewed hydrogels in ocular delivery (147). Residence time can be significantly enhanced with a hydrogel formulation. The gelation can be obtained by changing temperature and $\mathrm{pH}$. Poloxamers, the most widely used polymer, contain the hydrophobic part in the centre surrounded by a hydrophilic part. Though they are widely employed to enhance the residence time, they suffer from a major drawback of having weak mechanical strength, rapid erosion and non-biodegradability (148). Many attempts have been made to address this problem. Oligomerization was carried out to change the critical gelling temperature. In case of cellulose derivative like HPMC, gelation is a result of interaction of hydrophobic components at higher temperature (149). Pilocarpine formulation has shown enhanced miotic response at lower concentration of xyloglucan than poloxamer 407 (150). Pseudolatexes are artificial latexes obtained by dispersing pre-existing polymers in aqueous medium. They offer physical stability of gel along with the drug molecule which are sensitive to aqueous media (151).

In a different sort of gel approach also known as ATRIGEL, a polymer is dissolved in a suitable carrier. The polymer and carrier are both biodegradable and biocompatible. Once injected into the subcutaneous space, water in surrounding tissue causes the precipitation of polymer which immediately entraps the drug and releases it in a controlled manner (www.qlinc.com). The inventors of the product have claimed to use this system for a wide variety of molecules i.e. proteins and peptides. Targeted delivery of drugs, compatibility with a wide variety of molecules, potential to achieve controlled release and biocompatibility were the key features of the system (www.qlinc.com). Currently marketed product, 
Eligard $\AA$, represents a similar technology which is used for the treatment of prostate cancer. Table III summarizes recent development in hydrogel based formulations.

\section{IONTOPHORESIS}

Ocular iontophoresis has gained significant interest recently due to its non-invasive nature of delivery to both anterior and posterior segment. It requires a mild electric current which is applied to enhance ionized drug penetration into tissue. This mode of delivery can overcome the potential side effects associated with intraocular injections and implants mentioned earlier. OcuPhor ${ }^{\mathrm{TM}}$ system has been designed with an applicator, dispersive electrode and a dose controller for transscleral iontophoresis (DDT) $(152,153)$. This device releases the active drug into retina-choroid as well. A similar device has been designed called Visulex ${ }^{\mathrm{TM}}$ to allow selective transport of ionized molecules through sclera. Transcorneal and transscleral iontophoresis have been extensively employed to deliver a wide variety of drug molecules like gentamicin and dexamethasone. Delivery of antibiotics by iontophoresis has resulted in significant fewer bacterial colonies in cornea compared to the eye drops. Examples of antibiotics successfully employed are gentamicin, tobramycin and ciprofloxacin but not vancomycin because of its high molecular weight (154-156). Successful delivery was obtained with dexamethasone and with antisense ODNs $(157,158)$. A number of antibiotics, including gentamicin, cephazolin, ticarcilin, amikacin and vancomycin have been successfully delivered into the vitreous of rabbit eyes. Transscleral iontophoresis of steroids (dexamethasone and methyl prednisolone), amikacin, gentamicin and other drugs was also reported (159-164).

\section{MICRONEEDLE}

Recently, researchers have attempted microneedle to deliver drug to posterior segment as an alternative to topical route. The magnitude of lateral and transverse diffusion of sulforhodamine was found to be similar across human cadaver sclera. An evaluation of coated solid metal microneedle to deliver the drug was carried out both in-vitro and in-vivo. Microneedle had shown excellent in vitro penetration into sclera and rapid dissolution of coating solution after insertion. In-vivo drug level was found to be significantly higher than the level observed following topical drug administration. This mode of drug delivery was also successful in the delivery of pilocarpine (165). The inventors have claimed to deliver drug successfully across both sclera and cornea by coated microneedle with minimum invasion.

\section{GENE DELIVERY}

Recently, various strategies have been adopted to deliver nucleic acids to a specific site within the eye. Designing delivery system for antisense ODNs, aptamers or siRNAs is a challenging task for researchers in ocular delivery field because of high molecular weight, size, surface charge, solubility of the active drug and intrinsic complexities associated with the structure of ocular tissues like retina and cornea (105).

Table IV summarizes the recent developments happened in the field targeting various growth factors. Recently, FDA has approved Vitravene ${ }^{\circ}$, an ODNs for the treatment of CMV in AIDS patients and Macugen ${ }^{\circledR}$ (pegaptanib sodium injection) which is an aptamer for the treatment of "wet" AMD (209, 210). Non viral vectors have gained wide acceptance in gene delivery because of their ability to overcome disadvantages of viral vectors such as immunogenicity, safety and potential persistence in the brain (166-168). A major challenge associated with current system is its inability to achieve higher transfection efficiency. "Naked" DNA, physical vectorisation of the genetic material and chemical methods are three main modes of delivery among nonviral gene therapy. An extensive effort to deliver naked DNA by topical, intracameral, intracorneal, subconjunctival, intravitreal and by subretinal routes has been reviewed by Bloquel et al., (169). The same authors have described physical methods such as gene gun, electron transfer,

Table III. Recent Developments on the Hydrogel Based Formulations

\begin{tabular}{llll}
\hline \multicolumn{1}{c}{ Drug } & \multicolumn{1}{c}{ Polymer } & Mechanism of gelation \\
\hline Pefloxacin mesylate & Gelrite gellan gum & Ion & $(219)$ \\
Gatifloxacin & Alginate and HPMC & Ion & $(220)$ \\
Indomethacin & Gelrite $($ gellan gum) & Ion & $(221)$ \\
Ciprofloxacin HCL & Gelrite gellan gum and sodium alginate & Ion & $(222)$ \\
Gatifloxacin & & Ion & $(223)$ \\
Timolol maleate & Gellan gum & Ion & pH \\
Ofloxacin & Carbopol 940 and HPMC & pH & $(224)$ \\
Puerarin & Carbopol/HPMC-based gel & pH & $(226)$ \\
Puerarin & Poloxamer analogs/carbopol & - & $(227)$ \\
Fluconazole & In-situ gelling eye drops & - & $(228)$ \\
Ganciclovir & In-situ gelling eye drops & Temperature \\
Timolol maleate & Pluronic F127 & Temperature \\
Timolol maleate & poly(Nisopropylacrylamide)-chitosan & Ion and temperature \\
Pilocarpine & Alginate and pluronic-based in situ gelling & pH and temperature \\
Timolol maleate & Pluronic F-127 and chitosan & pH and temperature \\
Gatifloxacin & Pluronic F127-g-poly(acrylic acid) copolymers & Temperature \\
Pilocarpine & Xyloglucan & $(148)$ \\
\hline
\end{tabular}




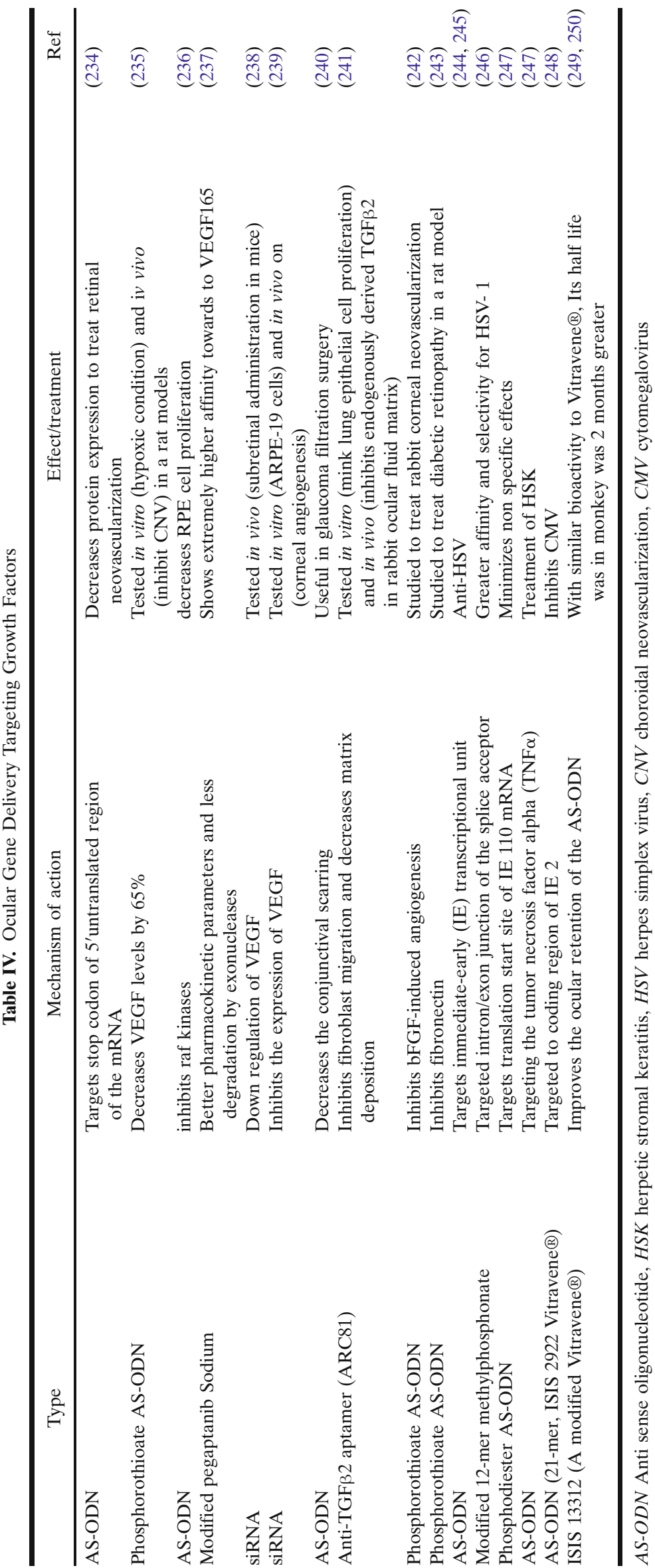


iontophoresis and ultrasound in this review. The authors have also focused on chemical methods such as liposomes, polyplexes, and PEGylated RNA aptamers.

\section{CONCLUSIONS}

Effective treatment of ocular diseases is a formidable challenge for scientists in the field especially because of the nature of diseases and presence of the ocular barriers especially in posterior ocular segments. An ideal therapy should maintain effective levels of drug for the longer duration following a single application. Drug delivery by topical and intravitreal routes cannot be considered safe, effective and patient friendly. Drug delivery by periocular route can potentially overcome many of these limitations and also can provide sustained drug levels in ocular pathologies affecting both segments. Transporter targeted delivery can be a promising strategy for many drug molecules. Colloidal carriers can substantially improve the current therapy and may emerge as an alternative following their periocular administration. In recent years, scientists have focused on designing a strategy with a multidisciplinary approach e.g. microneedle, iontophoresis and MRI. Continued innovation in gene delivery appears to be very exciting for a gamut of diseases. Designing these innovative techniques has given an unprecedented momentum for their protection by intellectual rights. In future, much of the emphasis will be given to achieve non-invasive sustained drug release for eye disorders in both segments. A clear understanding of the complexities associated with tissues in normal and pathological conditions, physiological barriers and multicompartmental pharmacokinetics would greatly hasten further development in the field.

\section{ACKNOWLEDGMENT}

We would like acknowledge NIH R01EY010659-12 and R01EY09171-15 for financial support.

\section{REFERENCES}

1. P. M. Hughes, and A. K. Mitra. Overview of ocular drug delivery and iatrogenic ocular cytopathologies. In: Mitra AK (2nd edition) Ophthalmic Drug Delivery Systems. New York: M. Dekker, Inc. 1-27 (1993).

2. J. C. Lang. Ocular drug delivery: conventional ocular formulations. Adv. Drug Delivery Rev. 16:39-43 (1995).

3. C. L. Bourlais, L. Acar, H. Zia, P.A. Sado, T. Needham, and R. Leverge. Ophthalmic drug delivery systems-recent advances. Prog. Retin. Eye Res. 17:33-58 (1998) doi:10.1016/S1350-9462 (97)00002-5.

4. R. Jain, S. Majumdar, Y. Nashed, D. Pal, and A. K. Mitra. Circumventing Pglycoprotein-mediated cellular efflux of quinidine by prodrug derivatization, Mol. Pharm. 1:290-299 (2004).

5. K. G. Janoria, S. Gunda, S. H. S. Boddu, A. K. Mitra. Novel approaches to retinal drug delivery. Expert Opin Drug Deliv. 4:371-388 (2007)

6. S. Raghava, M. Hammond, U. B. Kompella. Periocular routes for retinal drug delivery. Expert Opin Drug Deliv. 1:99-114 (2004).

7. C. S. Dias, B. S. Anand, A. K. Mitra. Effect of mono- and diacylation on the ocular disposition of ganciclovir: physicochemical properties, ocular bioreversion, and antiviral activity of short chain ester prodrugs. J. Pharm. Sci. 91:660-668 (2002).
8. F. Idrees, D. Vaideanu, S. Fraser, J. Sowden, P. Khaw. A review of anterior segment dysgeneses. Survey of Ophthal. 51:213-231 (2006).

9. H. Dayle. Geroski, H. F. Edelhauser. Drug Delivery for Posterior Segment Eye Disease. Invest. Ophthamol. Vis. Sci. 4:961-964 (2000).

10. V. H. Leeand, and J. R. Robinson. Topical ocular drug delivery: recent developments and future challenges. J. Ocul. Pharmacol. 2:67-108 (1986).

11. P. M. Hughes, O. Olejnik, J. E. Chang-Lin, and C. G. Wilson. Topical and systemic drug delivery to the posterior segments. Adv. Drug Deliv. Rev. 57:2010-2032 (2005) doi:10.1016/j. addr.2005.09.004.

12. I. Ahamed, T. F. Patton. Importance of the noncorneal absorption route in topical ophthalmic drug delivery. Invest. Ophthalmol. Vis. Sci. 26:584-587 (1985).

13. S. Duvvuri, S. Majumdar, and A. K. Mitra. Drug delivery to the retina: challenges and opportunities. Expert. Opin. Biol. Ther. 3:45-56 (2003) doi:10.1517/14712598.3.1.45.

14. M. F. Marmor, A. Negi, and D. M. Maurice. Kinetics of macromolecules injected into the subretinal space. Exp. Eye Res. 40:687-696 (1985) doi:10.1016/0014-4835(85)90138-1.

15. S. Ausayakhun, P. Yuvaves, S. Ngamtiphakom, and J. Prasitsilp. Treatment of cytomegalovirus retinitis in AIDS patients with intravitreal ganciclovir. J. Med. Assoc. Thai. 88(Suppl 9):S15S20 (2005)

16. S. Raghava, M. Hammond, and U. B. Kompella. Periocular routes for retinal drug delivery. Expert. Opin. Drug. Deliv. 1:99114 (2004) doi:10.1517/17425247.1.1.99.

17. D. Ghate, W. Brooks, B. E. McCarey, and H. F. Edelhauser. Pharmacokinetics of intraocular drug delivery by periocular injections using ocular fluorophotometry. Invest. Ophthalmol. Vis. Sci. 48:2230-2237 (2007) doi:10.1167/iovs.06-0954.

18. A. Castellarinand, and D. J. Pieramici. Anterior segment complications following periocular and intraocular injections. Ophthalmol. Clin. North Am. 17:583-590 (2004)vii.

19. V. Ganapathyand, and F. H. Leibach. Peptide transport in intestinal and renal brush border membrane vesicles. Life Sci. 30:2137-2146 (1982) doi:10.1016/0024-3205(82)90287-9.

20. S. A. Adibi. Renal assimilation of oligopeptides: physiological mechanisms and metabolic importance. Am. J. Physiol. 272 E723-736 (1997).

21. B. S. Anandand, and A. K. Mitra. Mechanism of corneal permeation of L-valyl ester of acyclovir: targeting the oligopeptide transporter on the rabbit cornea. Pharm. Res. 19:1194-1202 (2002) doi:10.1023/A:1019806411610.

22. S. M. Ocheltree, R. F. Keep, H. Shen, D. Yang, B. A. Hughes, and D. E. Smith. Preliminary investigation into the expression of proton-coupled oligopeptide transporters in neural retina and retinal pigment epithelium (RPE): lack of functional activity in RPE plasma membranes. Pharm. Res. 20:1364-1372 (2003) doi:10.1023/A:1025741723724.

23. H. Atluri, B. S. Anand, J. Patel, and A. K. Mitra. Mechanism of a model dipeptide transport across blood-ocular barriers following systemic administration. Exp. Eye Res. 78:815-822 (2004) doi:10.1016/j.exer.2003.10.020.

24. C. Dias, Y. Nashed, H. Atluri, and A. Mitra. Ocular penetration of acyclovir and its peptide prodrugs valacyclovir and valvalacyclovir following systemic administration in rabbits: An evaluation using ocular microdialysis and LC-MS. Curr. Eye Res. 25:243-252 (2002) doi:10.1076/ceyr.25.4.243.13488.

25. B. S. Winkler. Glycolytic and oxidative metabolism in relation to retinal function. J. Gen. Physiol. 77:667-692 (1981) doi:10.1085/jgp.77.6.667.

26. R. Merriman-Smith, P. Donaldson, and J. Kistler. Differential expression of facilitative glucose transporters GLUT1 and GLUT3 in the lens. Invest. Ophthalmol. Vis. Sci. 40:3224-3230 (1999).

27. G. J. Mantych, G. S. Hageman, and S. U. Devaskar. Characterization of glucose transporter isoforms in the adult and developing human eye. Endocrinology. 133:600-607 (1993) doi:10.1210/en.133.2.600.

28. R. F. Brubaker, W. M. Bourne, L. A. Bachman, and J. W. McLaren. Ascorbic acid content of human corneal epithelium. Invest. Ophthalmol. Vis. Sci. 41:1681-1683 (2000). 
29. W. J. Liang, D. Johnson, and S. M. Jarvis. Vitamin C transport systems of mammalian cells. Mol. Membr. Biol. 18:87-95 (2001) doi:10.1080/09687680110033774.

30. Y. Kanaiand, and M. A. Hediger. The glutamate/neutral amino acid transporter family SLC1: molecular, physiological and pharmacological aspects. Pflugers. Arch. 447:469-479 (2004) doi:10.1007/s00424-003-1146-4.

31. Y. Fukasawa, H. Segawa, J. Y. Kim, A. Chairoungdua, D. K. Kim, H. Matsuo, S. H. Cha, H. Endou, and Y. Kanai. Identification and characterization of a $\mathrm{Na}(+)$-independent neutral amino acid transporter that associates with the 4F2 heavy chain and exhibits substrate selectivity for small neutral D- and L-amino acids. J. Biol. Chem. 275:9690-9698 (2000) doi:10.1074/jbc.275.13.9690.

32. F. Verrey, C. Meier, G. Rossier, and L. C. Kuhn. Glycoproteinassociated amino acid exchangers: broadening the range of transport specificity. Pflugers. Arch. 440:503-512 (2000).

33. M. D. Gandhi, D. Pal, and A. K. Mitra. Identification and functional characterization of a $\mathrm{Na}(+)$-independent large neutral amino acid transporter (LAT2) on ARPE-19 cells. Int. $J$. Pharm. 275:189-200 (2004) doi:10.1016/j.ijpharm.2004.01.035.

34. B. Jain-Vakkalagadda, D. Pal, S. Gunda, Y. Nashed, V. Ganapathy, and A. K. Mitra. Identification of a $\mathrm{Na}+$-dependent cationic and neutral amino acid transporter, $\mathrm{B}(0,+)$, in human and rabbit cornea. Mol. Pharm. 1:338-346 (2004) doi:10.1021/ mp0499499.

35. M. E. Ganapathyand, and V. Ganapathy. Amino acid transporter ATB0,+as a delivery system for drugs and prodrugs. Curr. Drug Targets Immune. Endocr. Metabol. Disord. 5:357364 (2005) doi:10.2174/156800805774912953.

36. G. D. Eytanand, and P. W. Kuchel. Mechanism of action of Pglycoprotein in relation to passive membrane permeation. Int. Rev. Cytol. 190:175-250 (1999) doi:10.1016/S0074-7696(08) 62148-8.

37. M. Dean, A. Rzhetsky, and R. Allikmets. The human ATPbinding cassette $(\mathrm{ABC})$ transporter superfamily. Genome Res. 11:1156-1166 (2001) doi:10.1101/gr.GR-1649R.

38. B. Sarkadi, L. Homolya, G. Szakacs, and A. Varadi. Human multidrug resistance $\mathrm{ABCB}$ and $\mathrm{ABCG}$ transporters: participation in a chemoimmunity defense system. Physiol. Rev. 86:11791236 (2006) doi:10.1152/physrev.00037.2005.

39. F. J. Sharom. ABC multidrug transporters: structure, function and role in chemoresistance. Pharmacogenomics. 9:105-127 (2008) doi:10.2217/14622416.9.1.105.

40. W. T. Bellamy. P-glycoproteins and multidrug resistance. Annu. Rev. Pharmacol. Toxicol. 36:161-183 (1996) doi:10.1146/ annurev.pa.36.040196.001113.

41. M. M. Gottesmanand, and I. Pastan. Biochemistry of multidrug resistance mediated by the multidrug transporter. Annu. Rev. Biochem. 62:385-427 (1993) doi:10.1146/annurev. bi.62.070193.002125.

42. P. Saha, J.J. Yang, and V. H. Lee. Existence of a p-glycoprotein drug efflux pump in cultured rabbit conjunctival epithelial cells. Invest. Ophthalmol. Vis. Sci. 39:1221-1226 (1998).

43. J. Wu, J. J. Zhang, H. Koppel, and T. J. Jacob. P-glycoprotein regulates a volume-activated chloride current in bovine nonpigmented ciliary epithelial cells. J. Physiol. 491(Pt 3):743-755 (1996).

44. S. Dey, J. Patel, B. S. Anand, B. Jain-Vakkalagadda, P. Kaliki, D. Pal, V. Ganapathy, and A. K. Mitra. Molecular evidence and functional expression of P-glycoprotein (MDR1) in human and rabbit cornea and corneal epithelial cell lines. Invest. Ophthalmol. Vis. Sci. 44:2909-2918 (2003) doi:10.1167/iovs.02-1142.

45. J. A. Holashand, and P. A. Stewart. The relationship of astrocyte-like cells to the vessels that contribute to the bloodocular barriers. Brain Res. 629:218-224 (1993) doi:10.1016/ 0006-8993(93)91323-K.

46. P. A. Constable, J. G. Lawrenson, D. E. Dolman, G. B. Arden, and N. J. Abbott. P-Glycoprotein expression in human retinal pigment epithelium cell lines. Exp. Eye Res. 83:24-30 (2006) doi:10.1016/j.exer.2005.10.029.

47. H. Roelofsen, G. J. Hooiveld, H. Koning, R. Havinga, P. L. Jansen, and M. Muller. Glutathione S-conjugate transport in hepatocytes entering the cell cycle is preserved by a switch in expression from the apical MRP2 to the basolateral MRP1 transporting protein. J. Cell Sci. 112(Pt 9):1395-1404 (1999).

48. J. J. Yang, D. K. Ann, R. Kannan, and V. H. Lee. Multidrug resistance protein 1 (MRP1) in rabbit conjunctival epithelial cells: its effect on drug efflux and its regulation by adenoviral infection. Pharm. Res. 24:1490-1500 (2007) doi:10.1007/s11095-007-9267-7.

49. G. D. Kruh, Y. Guo, E. Hopper-Borge, M. G. Belinsky, and Z. S. Chen. ABCC10, ABCC11, and ABCC12. Pflugers. Arch. 453:675-684 (2007) doi:10.1007/s00424-006-0114-1.

50. J. V. Aukunuru, G. Sunkara, N. Bandi, W. B. Thoreson, and U. B. Kompella. Expression of multidrug resistance-associated protein (MRP) in human retinal pigment epithelial cells and its interaction with BAPSG, a novel aldose reductase inhibitor. Pharm. Res. 18:565-572 (2001) doi:10.1023/A:1011060705599.

51. H. Steuer, A. Jaworski, B. Elger, M. Kaussmann, J. Keldenich, H. Schneider, D. Stoll, and B. Schlosshauer. Functional characterization and comparison of the outer blood-retina barrier and the blood-brain barrier. Invest. Ophthalmol. Vis. Sci. 46:1047-1053 (2005) doi:10.1167/iovs.04-0925.

52. P. K. Karla, D. Pal, T. Quinn, and A. K. Mitra. Molecular evidence and functional expression of a novel drug efflux pump $(\mathrm{ABCC})$ in human corneal epithelium and rabbit cornea and its role in ocular drug efflux. Int. J. Pharm. 336:12-21 (2007) doi:10.1016/j.ijpharm.2006.11.031.

53. T. Zhang, C. D. Xiang, D. Gale, S. Carreiro, E. Y. Wu, and E. Y. Zhang. Drug transporter and cytochrome P450 mRNA expression in human ocular barriers: implications for ocular drug disposition. Drug Metab. Dispos. 36:1300-1307 (2008) doi:10.1124/dmd.108.021121.

54. Y. Shirasaki. Molecular design for enhancement of ocular penetration. J. Pharm. Sci. 97:2462-2496 (2008).

55. S. Gunda, S. Hariharan, and A. K. Mitra. Corneal absorption and anterior chamber pharmacokinetics of dipeptide monoester prodrugs of ganciclovir (GCV): in vivo comparative evaluation of these prodrugs with Val-GCV and GCV in rabbits. J. Ocul. Pharmacol. Ther. 22:465-476 (2006) doi:10.1089/ jop.2006.22.465.

56. S. Majumdar, Y. E. Nashed, K. Patel, R. Jain, M. Itahashi, D. M. Neumann, J. M. Hill, and A. K. Mitra. Dipeptide monoester ganciclovir prodrugs for treating HSV-1-induced corneal epithelial and stromal keratitis: in vitro and in vivo evaluations. $J$. Ocul. Pharmacol. Ther. 21:463-474 (2005) doi:10.1089/ jop.2005.21.463.

57. V. Kansara, Y. Hao, and A. K. Mitra. Dipeptide monoester ganciclovir prodrugs for transscleral drug delivery: targeting the oligopeptide transporter on rabbit retina. J. Ocul. Pharmacol. Ther. 23:321-334 (2007) doi:10.1089/jop.2006.0150.

58. K. G. Janoriaand, and A. K. Mitra. Effect of lactide/glycolide ratio on the in vitro release of ganciclovir and its lipophilic prodrug (GCV-monobutyrate) from PLGA microspheres. Int. J. Pharm. 338:133-141 (2007) doi:10.1016/j.ijpharm.2007.01.038.

59. B. S. Anand, J. M. Hill, S. Dey, K. Maruyama, P. S. Bhattacharjee, M. E. Myles, Y. E. Nashed, and A. K. Mitra. In vivo antiviral efficacy of a dipeptide acyclovir prodrug, valval-acyclovir, against HSV-1 epithelial and stromal keratitis in the rabbit eye model. Invest. Ophthalmol. Vis. Sci. 44:2529-2534 (2003) doi:10.1167/iovs.02-1251.

60. S. Katragadda, R. S. Talluri, and A. K. Mitra. Modulation of Pglycoprotein-mediated efflux by prodrug derivatization: an approach involving peptide transporter-mediated influx across rabbit cornea. J. Ocul. Pharmacol. Ther. 22:110-120 (2006) doi:10.1089/jop.2006.22.110.

61. J. Doukas, S. Mahesh, N. Umeda, S. Kachi, H. Akiyama, K. Yokoi, J. Cao, Z. Chen, L. Dellamary, B. Tam, A. RacanelliLayton, J. Hood, M. Martin, G. Noronha, R. Soll, and P. A. Campochiaro. Topical administration of a multi-targeted kinase inhibitor suppresses choroidal neovascularization and retinal edema. J. Cell Physiol. 216:29-37 (2008).

62. A. M. Al-Ghananeemand, and P. A. Crooks. Phase I and phase II ocular metabolic activities and the role of metabolism in ophthalmic prodrug and codrug design and delivery. Molecules. 12:373-388 (2007).

63. F. Lallemand, E. Varesio, O. Felt-Baeyens, L. Bossy, G. Hopfgartner, and R. Gurny. Biological conversion of a water- 
soluble prodrug of cyclosporine A. Eur. J. Pharm. Biopharm. 67:555-561 (2007) doi:10.1016/j.ejpb.2007.03.011.

64. J. Juntunen, T. Jarvinen, and R. Niemi. In-vitro corneal permeation of cannabinoids and their water-soluble phosphate ester prodrugs. J. Pharm. Pharmacol. 57:1153-1157 (2005) doi:10.1211/jpp.57.9.0009.

65. H. Nambu, R. Nambu, M. Melia, and P. A. Campochiaro. Combretastatin A-4 phosphate suppresses development and induces regression of choroidal neovascularization. Invest. Ophthalmol. Vis. Sci. 44:3650-3655 (2003) doi:10.1167/iovs.020985.

66. K. Takahashi, Y. Saishin, Y. Saishin, K. Mori, A. Ando, S. Yamamoto, Y. Oshima, H. Nambu, M. B. Melia, D. P. Bingaman, and P. A. Campochiaro. Topical nepafenac inhibits ocular neovascularization. Invest. Ophthalmol. Vis. Sci. 44:409-415 (2003) doi:10.1167/iovs.02-0346.

67. T. Yasukawa, Y. Ogura, Y. Tabata, H. Kimura, P. Wiedemann, and Y. Honda. Drug delivery systems for vitreoretinal diseases. Prog. Retin. Eye Res. 23:253-281 (2004) doi:10.1016/j. preteyeres.2004.02.003.

68. O. Kayser, A. Lemke, and N. Hernandez-Trejo. The impact of nanobiotechnology on the development of new drug delivery systems. Curr. Pharm. Biotechnol. 6:3-5 (2005).

69. J. Vandervoortand, and A. Ludwig. Ocular drug delivery: nanomedicine applications. Nanomed. 2:11-21 (2007) doi:10.2217/17435889.2.1.11.

70. M. J. Ansari, K. Kohli, and N. Dixit. Microemulsions as potential drug delivery systems: a review. PDA J. Pharm. Sci. Technol. 62:66-79 (2008).

71. T. F. Vandamme. Microemulsions as ocular drug delivery systems: recent developments and future challenges. Prog. Retin. Eye Res. 21:15-34 (2002) doi:10.1016/S1350-9462(01) 00017-9.

72. A. Hasse, and S. Keipert. Development and characterization of microemulsions for ocular application. Eur. J. Pharm. Biopharm. 43:179-183 (1997).

73. J. Chan, G. M. Maghraby, J. P. Craig, and R. G. Alany. Phase transition water-in-oil microemulsions as ocular drug delivery systems: in vitro and in vivo evaluation. Int. J. Pharm. 328:65-71 (2007) doi:10.1016/j.ijpharm.2006.10.004.

74. C. C. Li, M. Abrahamson, Y. Kapoor, and A. Chauhan. Timolol transport from microemulsions trapped in HEMA gels. $J$. Colloid Interface Sci. 315:297-306 (2007) doi:10.1016/j. jcis.2007.06.054

75. G. Buech, E. Bertelmann, U. Pleyer, I. Siebenbrodt, and H. H. Borchert. Formulation of sirolimus eye drops and corneal permeation studies. J. Ocul. Pharmacol. Ther. 23:292-303 (2007) doi:10.1089/jop.2006.130.

76. I. P. Kaurand, and M. Kanwar. Ocular preparations: the formulation approach. Drug Dev. Ind. Pharm. 28:473-493 (2002) doi:10.1081/DDC-120003445.

77. R. Pignatello, C. Bucolo, G. Spedalieri, A. Maltese, and G. Puglisi. Flurbiprofen-loaded acrylate polymer nanosuspensions for ophthalmic application. Biomaterials. 23:3247-3255 (2002) doi:10.1016/S0142-9612(02)00080-7.

78. K. Adibkia, Y. Omidi, M. R. Siahi, A. R. Javadzadeh, M. Barzegar-Jalali, J. Barar, N. Maleki, G. Mohammadi, and A. Nokhodchi. Inhibition of endotoxin-induced uveitis by methylprednisolone acetate nanosuspension in rabbits. J. Ocul. Pharmacol. Ther. 23:421-432 (2007) doi:10.1089/jop.2007.0039.

79. K. Adibkia, M. R. Siahi Shadbad, A. Nokhodchi, A. Javadzedeh, M. Barzegar-Jalali, J. Barar, G. Mohammadi, and Y. Omidi. Piroxicam nanoparticles for ocular delivery: physicochemical characterization and implementation in endotoxininduced uveitis. J. Drug Target. 15:407-416 (2007) doi:10.1080/ 10611860701453125.

80. M. A. Kassem, A. A. Abdel Rahman, M. M. Ghorab, M. B. Ahmed, and R. M. Khalil. Nanosuspension as an ophthalmic delivery system for certain glucocorticoid drugs. Int. J. Pharm. 340:126-133 (2007) doi:10.1016/j.ijpharm.2007.03.011.

81. R. Pignatello, N. Ricupero, C. Bucolo, F. Maugeri, A. Maltese, and G. Puglisi. Preparation and characterization of eudragit retard nanosuspensions for the ocular delivery of cloricromene. AAPS PharmSciTech. 7:E27 (2006) doi:10.1208/pt070127.
82. J. L. Bourges, S. E. Gautier, F. Delie, R. A. Bejjani, J. C. Jeanny, R. Gurny, D. BenEzra, and F. F. Behar-Cohen. Ocular drug delivery targeting the retina and retinal pigment epithelium using polylactide nanoparticles. Invest. Ophthalmol. Vis. Sci. 44:3562-3569 (2003) doi:10.1167/iovs.02-1068.

83. E. Sakurai, H. Ozeki, N. Kunou, and Y. Ogura. Effect of particle size of polymeric nanospheres on intravitreal kinetics. Ophthalmic. Res. 33:31-36 (2001) doi:10.1159/000055638.

84. V.H. Li, R.W. Wood, J. Kreuter, T. Harmia, and J. R. Robinson. Ocular drug delivery of progesterone using nanoparticles. $J$. Microencapsul. 3:213-218 (1986) doi:10.3109/02652048609031575.

85. R. Cavalli, M. R. Gasco, P. Chetoni, S. Burgalassi, and M. F. Saettone. Solid lipid nanoparticles (SLN) as ocular delivery system for tobramycin. Int. J. Pharm. 238:241-245 (2002) doi:10.1016/S0378-5173(02)00080-7.

86. A. C. Amrite, H. F. Edelhauser, S. R. Singh, and U. B. Kompella. Effect of circulation on the disposition and ocular tissue distribution of $20 \mathrm{~nm}$ nanoparticles after periocular administration. Mol. Vis. 14:150-160 (2008).

87. J. M. Irache, M. Merodio, A. Arnedo, M. A. Camapanero, M. Mirshahi, and S. Espuelas. Albumin nanoparticles for the intravitreal delivery of anticytomegaloviral drugs. Mini. Rev. Med. Chem. 5:293-305 (2005).

88. P. Calvo, J. L. Vila-Jato, M. J. Alonso. Comparative in vitro evaluation of several colloidal systems, nanoparticles, nanocapsules, and nanoemulsions, as ocular drug carriers. J Pharm Sci. 85:530-536 (1996).

89. A. M. De Campos, A. Sanchez, R. Gref, P. Calvo, and M. J. Alonso. The effect of a PEG versus a chitosan coating on the interaction of drug colloidal carriers with the ocular mucosa. Eur. J. Pharm. Sci. 20:73-81 (2003) doi:10.1016/S0928-0987(03)00178-7.

90. J. Xu, Y. Wang, Y. Li, X. Yang, P. Zhang, H. Hou, Y. Shi, and C. Song. Inhibitory efficacy of intravitreal dexamethasone acetateloaded PLGA nanoparticles on choroidal neovascularization in a laser-induced rat model. J. Ocul. Pharmacol. Ther. 23:527-540 (2007) doi:10.1089/jop.2007.0002.

91. S. K. Motwani, S. Chopra, S. Talegaonkar, K. Kohli, F. J. Ahmad, and R. K. Khar. Chitosan-sodium alginate nanoparticles as submicroscopic reservoirs for ocular delivery: formulation, optimisation and in vitro characterisation. Eur. J. Pharm. Biopharm. 68:513-525 (2008).

92. A. A. Moshfeghiand, and G. A. Peyman. Micro- and nanoparticulates. Adv. Drug Deliv. Rev. 57:2047-2052 (2005) doi:10.1016/j.addr.2005.09.006.

93. R. A. Bejjani, D. BenEzra, H. Cohen, J. Rieger, C. Andrieu, J. C. Jeanny, G. Gollomb, and F. F. Behar-Cohen. Nanoparticles for gene delivery to retinal pigment epithelial cells. Mol. Vis. 11:124-132 (2005)

94. A. Arnedo, J. M. Irache, M. Merodio, and M. S. Espuelas Millan. Albumin nanoparticles improved the stability, nuclear accumulation and anticytomegaloviral activity of a phosphodiester oligonucleotide. J. Control Release. 94:217-227 (2004) doi:10.1016/j.jconrel.2003.10.009.

95. A. Khan, W. Sommer, K. Fuxe, and S. Akhtar. Site-specific administration of antisense oligonucleotides using biodegradable polymer microspheres provides sustained delivery and improved subcellular biodistribution in the neostriatum of the rat brain. $J$. Drug. Target. 8:319-334 (2000) doi:10.3109/10611860008997909.

96. G. De Rosa, F. Quaglia, A. Bochot, F. Ungaro, and E. Fattal. Long-term release and improved intracellular penetration of oligonucleotide-polyethylenimine complexes entrapped in biodegradable microspheres. Biomacromolecules. 4:529-536 (2003) doi: $10.1021 / \mathrm{bm} 025684 \mathrm{c}$.

97. A. L. Gomes dos Santos, A. Bochot, A. Doyle, N. Tsapis, J. Siepmann, F. Siepmann, J. Schmaler, M. Besnard, F. BeharCohen, and E. Fattal. Sustained release of nanosized complexes of polyethylenimine and anti-TGF-beta 2 oligonucleotide improves the outcome of glaucoma surgery. J. Control Release. 112:369-381 (2006) doi:10.1016/j.jconrel.2006.02.010.

98. K. G. Carrasquillo, J. A. Ricker, I. K. Rigas, J. W. Miller, E. S. Gragoudas, and A. P. Adamis. Controlled delivery of the antiVEGF aptamer EYE001 with poly(lactic-co-glycolic)acid microspheres. Invest. Ophthalmol. Vis. Sci. 44:290-299 (2003) doi:10.1167/iovs.01-1156. 
99. Y. Shenand, and J. Tu. Preparation and ocular pharmacokinetics of ganciclovir liposomes. Aaps. J. 9:E371-377 (2007) doi:10.1208/aapsj0903044.

100. L. Lajavardi, A. Bochot, S. Camelo, B. Goldenberg, M. C. Naud, F. Behar-Cohen, E. Fattal, and Y. de Kozak. Downregulation of endotoxin-induced uveitis by intravitreal injection of vasoactive intestinal peptide encapsulated in liposomes. Invest. Ophthalmol. Vis. Sci. 48:3230-3238 (2007) doi:10.1167/iovs.06-1305.

101. L. Budai, M. Hajdu, M. Budai, P. Grof, S. Beni, B. Noszal, I. Klebovich, and I. Antal. Gels and liposomes in optimized ocular drug delivery: studies on ciprofloxacin formulations. Int. J. Pharm. 343:34-40 (2007) doi:10.1016/j.ijpharm.2007.04.013.

102. R. M. Hathout, S. Mansour, N. D. Mortada, and A. S. Guinedi. Liposomes as an ocular delivery system for acetazolamide: in vitro and in vivo studies. AAPS PharmSciTech. 8:1 (2007) doi:10.1208/pt0801001.

103. R. Cortesi, R. Argnani, E. Esposito, A. Dalpiaz, A. Scatturin, F. Bortolotti, M. Lufino, R. Guerrini, G. Cavicchioni, C. Incorvaia, E. Menegatti, and R. Manservigi. Cationic liposomes as potential carriers for ocular administration of peptides with anti-herpetic activity. Int. J. Pharm. 317:90-100 (2006) doi:10.1016/j.ijpharm.2006.02.050.

104. M. S. Nagarsenker, V. Y. Londhe, and G. D. Nadkarni. Preparation and evaluation of liposomal formulations of tropicamide for ocular delivery. Int. J. Pharm. 190:63-71 (1999) doi:10.1016/S0378-5173(99)00265-3.

105. A. Bochot, B. Mashhour, F. Puisieux, P. Couvreur, and E. Fattal. Comparison of the ocular distribution of a model oligonucleotide after topical instillation in rabbits of conventional and new dosage forms. J. Drug Target. 6:309-313 (1998).

106. A. Bochot, E. Fattal, V. Boutet, J. R. Deverre, J. C. Jeanny, H. Chacun, and P. Couvreur. Intravitreal delivery of oligonucleotides by sterically stabilized liposomes. Invest. Ophthalmol. Vis. Sci. 43:253-259 (2002).

107. N. Ogata, T. Otsuji, M. Matsushima, T. Kimoto, R. Yamanaka, K. Takahashi, M. Wada, M. Uyama, and Y. Kaneda. Phosphorothioate oligonucleotides induction into experimental choroidal neovascularization by HVJ-liposome system. Curr. Eye Res. 18:261-269 (1999) doi:10.1076/ceyr.18.4.261.5358.

108. I. P. Kaur, A. Garg, A. K. Singla, and D. Aggarwal. Vesicular systems in ocular drug delivery: an overview. Int. J. Pharm. 269:1-14 (2004) doi:10.1016/j.ijpharm.2003.09.016.

109. S. P. Vyas, N. Mysore, V. Jaitely, and N. Venkatesan. Discoidal niosome based controlled ocular delivery of timolol maleate. Pharmazie. 53:466-469 (1998).

110. A. Quintana, E. Raczka, L. Piehler, I. Lee, A. Myc, I. Majoros, A.K. Patri, T. Thomas, J. Mule, and J. R. Baker Jr. Design and function of a dendrimer-based therapeutic nanodevice targeted to tumor cells through the folate receptor. Pharm. Res. 19:13101316 (2002) doi:10.1023/A:1020398624602.

111. H. R. Ihre, O. L. Padilla De Jesus, F. C. Szoka Jr., and J. M. Frechet. Polyester dendritic systems for drug delivery applications: design, synthesis, and characterization. Bioconjug. Chem. 13:443-452 (2002) doi:10.1021/bc010102u.

112. T. F. Pattonand, and J. R. Robinson. Ocular evaluation of polyvinyl alcohol vehicle in rabbits. J. Pharm. Sci. 64:1312-1316 (1975) doi:10.1002/jps.2600640811.

113. O. M. Milhem, C. Myles, N. B. McKeown, D. Attwood, and A. D'Emanuele. Polyamidoamine starburst dendrimers as solubility enhancers. Int. J. Pharm. 197:239-241 (2000) doi:10.1016/ S0378-5173(99)00463-9.

114. D. Bhadra, S. Bhadra, S. Jain, and N. K. Jain. A PEGylated dendritic nanoparticulate carrier of fluorouracil. Int. J. Pharm. 257:111-124 (2003) doi:10.1016/S0378-5173(03)00132-7.

115. T. Ooya, J. Lee, and K. Park. Effects of ethylene glycol-based graft, star-shaped, and dendritic polymers on solubilization and controlled release of paclitaxel. J. Control Release. 93:121-127 (2003) doi:10.1016/j.jconrel.2003.07.001.

116. T. F. Vandammeand, and L. Brobeck. Poly(amidoamine) dendrimers as ophthalmic vehicles for ocular delivery of pilocarpine nitrate and tropicamide. J. Control Release. 102:23-38 (2005) doi:10.1016/j.jconrel.2004.09.015.

117. S. Shaunak, S. Thomas, E. Gianasi, A. Godwin, E. Jones, I. Teo, K. Mireskandari, P. Luthert, R. Duncan, S. Patterson, P. Khaw, and S. Brocchini. Polyvalent dendrimer glucosamine conjugates prevent scar tissue formation. Nat Biotechnol. 22:977-984 (2004) doi:10.1038/nbt995.

118. X. Duanand, and H. Sheardown. Dendrimer crosslinked collagen as a corneal tissue engineering scaffold: mechanical properties and corneal epithelial cell interactions. Biomaterials. 27:4608-4617 (2006) doi:10.1016/j.biomaterials.2006.04.022.

119. R. J. Marano, I. Toth, N. Wimmer, M. Brankov, and P. E. Rakoczy. Dendrimer delivery of an anti-VEGF oligonucleotide into the eye: a long-term study into inhibition of laser-induced $\mathrm{CNV}$, distribution, uptake and toxicity. Gene. therapy. 12:15441550 (2005) doi:10.1038/sj.gt.3302579.

120. T. Loftssonaand, and T. Jarvinen. Cyclodextrins in ophthalmic drug delivery. Adv. Drug Deliv. Rev. 36:59-79 (1999) doi:10.1016/S0169-409X(98)00055-6.

121. Y. Aktas, N. Unlu, M. Orhan, M. Irkec, and A. A. Hincal. Influence of hydroxypropyl beta-cyclodextrin on the corneal permeation of pilocarpine. Drug Dev. Ind. Pharm. 29:223-230 (2003) doi:10.1081/DDC-120016730.

122. H. H. Sigurdsson, F. Konraethsdottir, T. Loftsson, and E. Stefansson. Topical and systemic absorption in delivery of dexamethasone to the anterior and posterior segments of the eye. Acta. Ophthalmol. Scand. 85:598-602 (2007) doi:10.1111/ j.1600-0420.2007.00885.x.

123. S. Wang, D. Li, Y. Ito, X. Liu, J. Zhang, and C. Wu. An ocular drug delivery system containing zinc diethyldithiocarbamate and HPbetaCD inclusion complex-corneal permeability, anticataract effects and mechanism studies. J. Pharm. Pharmacol. 56:1251-1257 (2004) doi:10.1211/0022357044526.

124. S. Wang, D. Li, Y. Ito, T. Nabekura, S. Wang, J. Zhang, and C. $\mathrm{Wu}$. Bioavailability and anticataract effects of a topical ocular drug delivery system containing disulfiram and hydroxypropylbeta-cyclodextrin on selenite-treated rats. Curr. Eye Res. 29:5158 (2004) doi:10.1080/02713680490513209.

125. E. Y. Kim, Z. G. Gao, J. S. Park, H. Li, and K. Han. rhEGF/HPbeta-CD complex in poloxamer gel for ophthalmic delivery. Int. J. Pharm. 233:159-167 (2002) doi:10.1016/S0378-5173(01)00933-4.

126. K. A. Freedman, J. W. Klein, and C. E. Crosson. Betacyclodextrins enhance bioavailability of pilocarpine. Curr. Eye Res. 12:641-647 (1993) doi:10.3109/02713689309001843.

127. A. Usayapant, A. H. Karara, and M. M. Narurkar. Effect of 2hydroxypropyl-beta-cyclodextrin on the ocular absorption of dexamethasone and dexamethasone acetate. Pharm. Res. 8:1495-1499 (1991) doi:10.1023/A:1015838215268.

128. L. Xinming, C. Yingde, A. W. Lloyd, S. V. Mikhalovsky, S. R. Sandeman, C. A. Howel, and L. Liewen. Polymeric hydrogels for novel contact lens-based ophthalmic drug delivery systems: A review. Cont. Lens. Anterior. Eye. 31:57-64 (2008) doi:10.1016/j.clae.2007.09.002.

129. Y. Kapoorand, and A. Chauhan. Drug and surfactant transport In Cyclosporine A and Brij 98 laden p-HEMA hydrogels. J. Colloid Interface Sci. 322:624-633 (2008) doi:10.1016/j.jcis.2008.02.028.

130. J. Kimand, and A. Chauhan. Dexamethasone transport and ocular delivery from poly(hydroxyethyl methacrylate) gels. Int. J. Pharm. 353:205-222 (2008).

131. J. Kim, A. Conway, and A. Chauhan. Extended delivery of ophthalmic drugs by silicone hydrogel contact lenses. Biomaterials. 29:2259-2269 (2008) doi:10.1016/j.biomaterials.2008.01.030.

132. N. A. McNamara, K. A. Polse, R. J. Brand, A. D. Graham, J. S. Chan, and C. D. McKenney. Tear mixing under a soft contact lens: effects of lens diameter. Am. J. Ophthalmol. 127:659-665 (1999) doi:10.1016/S0002-9394(99)00051-3.

133. D. Gulsenand, and A. Chauhan. Ophthalmic drug delivery through contact lenses. Invest Ophthalmol Vis Sci. 45:2342-2347 (2004) doi:10.1167/iovs.03-0959.

134. J. L. Bourges, C. Bloquel, A. Thomas, F. Froussart, A. Bochot, F. Azan, R. Gurny, D. BenEzra, and F. Behar-Cohen. Intraocular implants for extended drug delivery: therapeutic applications. Adv. Drug Deliv. Rev. 58:1182-1202 (2006) doi:10.1016/j. addr.2006.07.026.

135. T. Yasukawa, H. Kimura, Y. Tabata, and Y. Ogura. Biodegradable scleral plugs for vitreoretinal drug delivery. Adv. Drug Deliv. Rev. 52:25-36 (2001) doi:10.1016/S0169409X(01)00192-2.

136. T. Yasukawa, Y. Ogura, E. Sakurai, Y. Tabata, and H. Kimura. Intraocular sustained drug delivery using implantable polymeric 
devices. Adv. Drug Deliv. Rev. 57:2033-2046 (2005) doi:10.1016/ j.addr.2005.09.005.

137. N. Kunou, Y. Ogura, T. Yasukawa, H. Kimura, H. Miyamoto, Y. Honda, and Y. Ikada. Long-term sustained release of ganciclovir from biodegradable scleral implant for the treatment of cytomegalovirus retinitis. J. Control Release. 68:263-271 (2000) doi:10.1016/S0168-3659(00)00267-4.

138. X. Dong, W. Shi, G. Yuan, L. Xie, S. Wang, and P. Lin. Intravitreal implantation of the biodegradable cyclosporin A drug delivery system for experimental chronic uveitis. Graefes. Arch. Clin. Exp. Ophthalmol. 244:492-497 (2006) doi:10.1007/ s00417-005-0109-1.

139. W. Shi, T. Liu, L. Xie, and S. Wang. FK506 in a biodegradable glycolide-co-clatide-co-caprolactone polymer for prolongation of corneal allograft survival. Curr. Eye Res. 30:969-976 (2005) doi:10.1080/02713680500320752.

140. K. W. Leong, P. D. D'Amore, M. Marletta, and R. Langer. Bioerodible polyanhydrides as drug-carrier matrices. II. Biocompatibility and chemical reactivity. J. Biomed. Mater. Res. 20:51-64 (1986) doi:10.1002/jbm.820200106.

141. S. Y. Ng, H. R. Shen, E. Lopez, Y. Zherebin, J. Barr, E. Schacht, and J. Heller. Development of a poly(ortho ester) prototype with a latent acid in the polymer backbone for 5-fluorouracil delivery. J. Control Release. 65:367-374 (2000) doi:10.1016/ S0168-3659(99)00218-7.

142. Y. Uteza, J. S. Rouillot, A. Kobetz, D. Marchant, S. Pecqueur, E. Arnaud, H. Prats, J. Honiger, J. L. Dufier, M. Abitbol, and M. Neuner-Jehle. Intravitreous transplantation of encapsulated fibroblasts secreting the human fibroblast growth factor 2 delays photoreceptor cell degeneration in Royal College of Surgeons rats. Proc. Natl. Acad. Sci. U. S. A. 96:3126-3131 (1999) doi:10.1073/pnas.96.6.3126.

143. W. Tao, R. Wen, M. B. Goddard, S. D. Sherman, P. J. O'Rourke, P. F. Stabila, W. J. Bell, B. J. Dean, K. A. Kauper, V. A. Budz, W. G. Tsiaras, G. M. Acland, S. Pearce-Kelling, A. M. Laties, and G. D. Aguirre. Encapsulated cell-based delivery of CNTF reduces photoreceptor degeneration in animal models of retinitis pigmentosa. Invest. Ophthalmol. Vis. Sci. 43:32923298 (2002).

144. R. A. Bush, B. Lei, W. Tao, D. Raz, C. C. Chan, T. A. Cox, M. Santos-Muffley, and P. A. Sieving. Encapsulated cell-based intraocular delivery of ciliary neurotrophic factor in normal rabbit: dosedependent effects on ERG and retinal histology. Invest. Ophthalmol. Vis. Sci. 45:2420-2430 (2004) doi:10.1167/iovs.03-1342.

145. C. G. Thanos, W. J. Bell, P. O'Rourke, K. Kauper, S. Sherman, P. Stabila, and W. Tao. Sustained secretion of ciliary neurotrophic factor to the vitreous, using the encapsulated cell therapy-based NT-501 intraocular device. Tissue Eng. 10:16171622 (2004) doi:10.1089/ten.2004.10.1617.

146. P. A. Sieving, R. C. Caruso, W. Tao, H. R. Coleman, D. J. Thompson, K. R. Fullmer, and R. A. Bush. Ciliary neurotrophic factor (CNTF) for human retinal degeneration: phase I trial of CNTF delivered by encapsulated cell intraocular implants. Proc. Natl. Acad. Sci. U. S. A. 103:3896-3901 (2006) doi:10.1073/pnas.0600236103.

147. B. K. Nanjawade, F. V. Manvi, and A. S. Manjappa. In situ-forming hydrogels for sustained ophthalmic drug delivery. J. Control Release. 122:119-134 (2007) doi:10.1016/j.jconrel. 2007.07.009.

148. A. H. El-Kamel. In vitro and in vivo evaluation of Pluronic F127-based ocular delivery system for timolol maleate. Int. J. Pharm. 241:47-55 (2002) doi:10.1016/S0378-5173(02)00234-X.

149. E. Ruel-Gariepy, and J. C. Leroux. In situ-forming hydrogelsreview of temperature-sensitive systems. Eur. J. Pharm. Biopharm. 58:409-426 (2004) doi:10.1016/j.ejpb.2004.03.019.

150. S. Miyazaki, S. Suzuki, N. Kawasaki, K. Endo, A. Takahashi, and D. Attwood. In situ gelling xyloglucan formulations for sustained release ocular delivery of pilocarpine hydrochloride. Int. J. Pharm. 229:29-36 (2001) doi:10.1016/S0378-5173(01)00825-0.

151. S. P. Vyas, S. Ramchandraiah, C. P. Jain, S. K. Jain. Polymeric pseudolatices bearing pilocarpine for controlled ocular delivery. J Microencapsul. 9:347-355 (1992).

152. T. M. Parkinson, E. Ferguson, S. Febbraro, A. Bakhtyari, M. King, and M. Mundasad. Tolerance of ocular iontophoresis in healthy volunteers. J. Ocul. Pharmacol. Ther. 19:145-151 (2003) doi:10.1089/108076803321637672.
153. D. L. Vollmer, M. A. Szlek, K. Kolb, L. B. Lloyd, and T. M. Parkinson. In vivo transscleral iontophoresis of amikacin to rabbit eyes. J. Ocul. Pharmacol. Ther. 18:549-558 (2002) doi:10.1089/108076802321021090.

154. J. Frucht-Pery, F. Raiskup, H. Mechoulam, M. Shapiro, E. Eljarrat-Binstock, and A. Domb. Iontophoretic treatment of experimental pseudomonas keratitis in rabbit eyes using gentamicin-loaded hydrogels. Cornea. 25:1182-1186 (2006) doi:10.1097/01.ico.0000243959.14651.18.

155. J. A. Hobden, R. J. O'Callaghan, J. M. Hill, J. J. Reidy, D. S. Rootman, and H.W. Thompson. Tobramycin iontophoresis into corneas infected with drug-resistant Pseudomonas aeruginosa. Curr. Eye Res. 8:1163-1169 (1989) doi:10.3109/02713688909000041.

156. J. A. Hobden, J. J. Reidy, R. J. O'Callaghan, M. S. Insler, and J. M. Hill. Ciprofloxacin iontophoresis for aminoglycoside-resistant pseudomonal keratitis. Invest. Ophthalmol. Vis. Sci. 31:1940-1944 (1990).

157. E. Eljarrat-Binstock, F. Raiskup, J. Frucht-Pery, and A. J. Domb. Transcorneal and transscleral iontophoresis of dexamethasone phosphate using drug loaded hydrogel. J. Control Release. 106:386-390 (2005) doi:10.1016/j.jconrel.2005.05.020.

158. M. Berdugo, F. Valamanesh, C. Andrieu, C. Klein, D. Benezra, Y. Courtois, and F. Behar-Cohen. Delivery of antisense oligonucleotide to the cornea by iontophoresis. Antisense Nucleic. Acid. Drug Dev. 13:107-114 (2003) doi:10.1089/108729003321629647.

159. M. Barza, C. Peckman, and J. Baum. Transscleral iontophoresis of cefazolin, ticarcillin, and gentamicin in the rabbit. Ophthalmology. 93:133-139 (1986).

160. F. F. Behar-Cohen, A. El Aouni, S. Gautier, G. David, J. Davis, P. Chapon, and J. M. Parel. Transscleral Coulomb-controlled iontophoresis of methylprednisolone into the rabbit eye: influence of duration of treatment, current intensity and drug concentration on ocular tissue and fluid levels. Exp. Eye Res. 74:51-59 (2002) doi:10.1006/exer.2001.1098.

161. B. C. Hayden, M. E. Jockovich, T. G. Murray, M. Voigt, P. Milne, M. Kralinger, W. J. Feuer, E. Hernandez, and J. M. Parel. Pharmacokinetics of systemic versus focal carboplatin chemotherapy in the rabbit eye: possible implication in the treatment of retinoblastoma. Invest. Ophthalmol. Vis. Sci. 45:3644-3649 (2004) doi:10.1167/iovs.04-0228.

162. R. E. Grossman, D. F. Chu, and D. A. Lee. Regional ocular gentamicin levels after transcorneal and transscleral iontophoresis. Invest. Ophthalmol. Vis. Sci. 31:909-916 (1990).

163. D. Sarraf, R. A. Equi, G. N. Holland, M. O. Yoshizumi, and D. A. Lee. Transscleral iontophoresis of foscarnet. Am. J. ophthalmol. 115:748-754 (1993).

164. T. T. Lam, J. Fu, R. Chu, K. Stojack, E. Siew, and M. O. Tso Intravitreal delivery of ganciclovir in rabbits by transscleral iontophoresis. J. Ocul. Pharmacol. 10:571-575 (1994).

165. J. Jiang, H. S. Gill, D. Ghate, B. E. McCarey, S. R. Patel, H. F. Edelhauser, and M. R. Prausnitz. Coated microneedles for drug delivery to the eye. Invest. Ophthalmol. Vis. Sci. 48:4038-4043 (2007) doi:10.1167/iovs.07-0066.

166. K. Joossand, and N. Chirmule. Immunity to adenovirus and adeno-associated viral vectors: implications for gene therapy. Gene. Therapy. 10:955-963 (2003) doi:10.1038/sj.gt.3302037.

167. N. Bessis, F. J. GarciaCozar, and M. C. Boissier. Immune responses to gene therapy vectors: influence on vector function and effector mechanisms. Gene. Therapy. 11(Suppl 1):S10-S17 (2004) doi:10.1038/sj.gt.3302364.

168. N. Provost, G. Le Meur, M. Weber, A. Mendes-Madeira, G. Podevin, Y. Cherel, M. A. Colle, J. Y. Deschamps, P. Moullier, and F. Rolling. Biodistribution of rAAV vectors following intraocular administration: evidence for the presence and persistence of vector DNA in the optic nerve and in the brain. Mol. Ther. 11:275-283 (2005) doi:10.1016/j.ymthe.2004.09.022.

169. C. Bloquel, J. L. Bourges, E. Touchard, M. Berdugo, D. BenEzra, and F. Behar-Cohen. Non-viral ocular gene therapy: potential ocular therapeutic avenues. Adv. Drug Deliv. Rev. 58:1224-1242 (2006) doi:10.1016/j.addr.2006.07.023.

170. R. Klein, T. Peto, A. Bird, and M. R. Vannewkirk. The epidemiology of age-related macular degeneration. Am. J. Ophthalmol. 137:486-495 (2004) doi:10.1016/j.ajo.2003.11.069/.

171. H. M. Leibowitz, D. E. Krueger, L. R. Maunder, R. C. Milton, M. M. Kini, H. A. Kahn, R. J. Nickerson, J. Pool, T. L. Colton, 
J. P. Ganley, J. I. Loewenstein, and T. R. Dawber. The Framingham Eye Study monograph: an ophthalmological and epidemiological study of cataract, glaucoma, diabetic retinopathy, macular degeneration, and visual acuity in a general population of 2631 adults, 1973-1975. Surv. Ophthalmol. 24:335-610 (1980) doi:10.1016/0039-6257(80)90015-6.

172. L. P. Iuand, and A. K. Kwok. An update of treatment options for neovascular age-related macular degeneration. Hong Kong Med. J. 13:460-470 (2007).

173. J. S. Sunness, G. S. Rubin, C. A. Applegate, N. M. Bressler, M. J. Marsh, B. S. Hawkins, and D. Haselwood. Visual function abnormalities and prognosis in eyes with age-related geographic atrophy of the macula and good visual acuity. Ophthalmology. 104:1677-1691 (1997)

174. K. Spilsbury, K. L. Garrett, W. Y. Shen, I. J. Constable, and P. E. Rakoczy. Overexpression of vascular endothelial growth factor (VEGF) in the retinal pigment epithelium leads to the development of choroidal neovascularization. Am. J. Pathol. 157:135-144 (2000).

175. U. Schmidt-Erfurth, H. Laqua, U. Schlotzer-Schrehard, A. Viestenz, and G. O. Naumann. Histopathological changes following photodynamic therapy in human eyes. Arch. Ophthalmol. 120:835-844 (2002).

176. M. Nobrega, C. Bortolotto, and M. Farah. Combined photodynamic therapy and intravitreal triamcinolone injection for choroidal neovascularization in Best disease. Can. J. Ophthalmol. 42:761-762 (2007) doi:10.3129/I07-138.

177. G. Virgiliand, and A. Bini. Laser photocoagulation for neovascular age-related macular degeneration. Cochrane Database Syst. Rev.:CD004763 (2007).

178. R. A. Costa, R. Jorge, D. Calucci, J. A. Cardillo, L. A. Melo Jr., and I. U. Scott. Intravitreal bevacizumab for choroidal neovascularization caused by AMD (IBeNA Study): results of a phase 1 dose-escalation study. Investig. Ophthalmol. Vis. Sci. 47:4569-4578 (2006) doi:10.1167/iovs.06-0433.

179. R. Klein, B. E. Klein, S. E. Moss, M. D. Davis, and D. L. DeMets. The Wisconsin epidemiologic study of diabetic retinopathy. IV. Diabetic macular edema. Ophthalmology. 91:1464 1474 (1984).

180. C. H. Meyer. Current treatment approaches in diabetic macular edema. Ophthalmologica. 221:118-131 (2007) doi:10.1159/ 000098257.

181. F. Bandello, R. Pognuz, A. Polito, A. Pirracchio, F. Menchini, and M. Ambesi. Diabetic macular edema: classification, medical and laser therapy. Semin. Ophthalmol. 18:251-258 (2003) doi:10.1080/08820530390895262.

182. D. G. Charteris. Proliferative vitreoretinopathy: pathobiology, surgical management, and adjunctive treatment. Br J Ophthalmol. 79:953-960 (1995).

183. S. Scheer, C. Morel, O. Touzeau, J. A. Sahel, L. Laroche. Pharmacological adjuvants for surgical treatment of proliferative vitreoretinopathy. J Fr Ophtalmol. 2:1051-1059 (2004).

184. R. H. Asaria, C. H. Kon, C. Bunce, D. G. Charteris, D. Wong, P. T. Khaw, and G. W. Aylward. Adjuvant 5-fluorouracil and heparin prevents proliferative vitreoretinopathy: results from a randomized, double-blind, controlled clinical trial. Ophthalmology. 108:1179-1183 (2001) doi:10.1016/S0161-6420(01)00589-9.

185. J. V. Forrester. Endogenous posterior uveitis. Br. J. Ophthalmol. 74:620-623 (1990) doi:10.1136/bjo.74.10.620.

186. J. V. Forrester. Intermediate and posterior uveitis. Chem. Immunol. Allergy. 92:228-243 (2007) doi:10.1159/000099274.

187. S. Lightman. Use of steroids and immunosuppressive drugs in the management of posterior uveitis. Eye. 5(Pt 3):294-298 (1991)

188. J. T. Holbrook, D. A. Jabs, D. V. Weinberg, R. A. Lewis, M. D. Davis, and D. Friedberg. Visual loss in patients with cytomegalovirus retinitis and acquired immunodeficiency syndrome before widespread availability of highly active antiretroviral therapy. Arch. Ophthalmol. 121:99-107 (2003).

189. M. A. Jacobson, H. Stanley, C. Holtzer, T. P. Margolis, and E. T. Cunningham. Natural history and outcome of new AIDS-related cytomegalovirus retinitis diagnosed in the era of highly active antiretroviral therapy. Clin. Infect. Dis. 30:231-233 (2000).

190. P. F. Hoyngand, and L.M. van Beek. Pharmacological therapy for glaucoma: a review. Drugs. 59:411-434 (2000) doi:10.2165/ 00003495-200059030-00003.
191. C. B. Camras, L. Z. Bito, and K. E. Eakins. Reduction of intraocular pressure by prostaglandins applied topically to the eyes of conscious rabbits. Investig. Ophthalmol. Vis. Sci. 16:1125-1134 (1977).

192. A. Billand, and K. Heilmann. Ocular effects of clonidine in cats and monkeys (Macaca irus). Exp. Eye Res. 21:481-488 (1975) doi:10.1016/0014-4835(75)90129-3.

193. P. L. Kaufmanand, and E. H. Barany. Residual pilocarpine effects on outflow facility after ciliary muscle disinsertion in the synomolgus monkey. Invest. Ophthalmol. 15:558-561 (1976)

194. B. R. Friedland, J. Mallonee, and D. R. Anderson. Short-term dose response characteristics of acetazolamide in man. Arch. Ophthalmol. 95:1809-1812 (1977).

195. K. Wickstrom. Acute bacterial conjunctivitis-benefits versus risks with antibiotic treatment. Acta. Ophthalmol. $(O x f)$. 86:2-4 (2008).

196. C. Riva, P. Perlino, A. Valpreda, E. Ricotti, G. Castagneri, L. Balbo, and A. Musso. Long lasting conjunctivitis: research of etiological factors. Minerva Pediatr. 44:595-600 (1992).

197. J. P. McCulley. Blepharoconjunctivitis. Int. Ophthalmol. Clin. 24:65-77 (1984) doi:10.1097/00004397-198402420-00008.

198. D. Warren, K. E. Nelson, J. A. Farrar, E. Hurwitz, J Hierholzer, E. Ford, and L. J. Anderson. A large outbreak of epidemic keratoconjunctivitis: problems in controlling nosocomial spread. J. Infect. Dis. 160:938-943 (1989).

199. D. Balasubramanian, A. K. Bansal, S. Basti, K. S. Bhatt, J. S. Murthy, and C. M. Rao. The biology of cataract. The Hyderabad Cataract Research Group. Indian J. Ophthalmol. 41:153-171 (1993).

200. S. Bastiand, and M. J. Greenwald. Principles and paradigms of pediatric cataract management. Indian J. Ophthalmol. 43:159176 (1995).

201. H. A. Kahn, H. M. Leibowitz, J. P. Ganley, M. M. Kini, T Colton, R. S. Nickerson, and T. R. Dawber. The Framingham Eye Study. I. Outline and major prevalence findings. Am. J. Epidemiol. 106:17-32 (1977).

202. D. A. Quillen. Common causes of vision loss in elderly patients. Am. Fam. Phys. 60:99-108 (1999).

203. Y. R. Sharma, R. B. Vajpayee, R. Bhatnagar, M. Mohan, R. V. Azad, M. Kumar, and R. Nath. A simple accurate method of cataract classification. Cataract-I. Indian J. Ophthalmol. 37:112117 (1989).

204. A. Kato, H. Kimura, K. Okabe, J. Okabe, N. Kunou, and Y. Ogura. Feasibility of drug delivery to the posterior pole of the rabbit eye with an episcleral implant. Investig. Ophthalmol. Vis. Sci. 45:238-244 (2004) doi:10.1167/iovs.02-1258.

205. T. A. Ciulla, M. H. Criswell, R. P. Danis, M. Fronheiser, P. Yuan, T. A. Cox, K. G. Csaky, and M. R. Robinson. Choroidal neovascular membrane inhibition in a laser treated rat model with intraocular sustained release triamcinolone acetonide microimplants. Br. J. Ophthalmol. 87:1032-1037 (2003) doi:10.1136/bjo.87.8.1032.

206. S. K. Seah, R. Husain, G. Gazzard, M. C. Lim, S. T. Hoh, F. T. Oen, and T. Aung. Use of surodex in phacotrabeculectomy surgery. Am. J. Ophthalmol. 139:927-928 (2005) doi:10.1016/j. ajo.2004.10.052.

207. L. Xie, W. Shi, Z. Wang, J. Bei, and S. Wang. Prolongation of corneal allograft survival using cyclosporine in a polylactide-coglycolide polymer. Cornea. 20:748-752 (2001) doi:10.1097/ 00003226-200110000-00015.

208. S. Einmahl, F. Behar-Cohen, F. D'Hermies, S. Rudaz, C. Tabatabay, G. Renard, and R. Gurny. A new poly(ortho ester)based drug delivery system as an adjunct treatment in filtering surgery. Investig. Ophthalmol. Vis. Sci. 42:695-700 (2001).

209. T. Zhou, H. Lewis, R. E. Foster, and S. P. Schwendeman. Development of a multiple-drug delivery implant for intraocular management of proliferative vitreoretinopathy. J. Control Release. 55:281-295 (1998) doi:10.1016/S0168-3659(98)00061-3.

210. T. Yasukawa, H. Kimura, Y. Tabata, H. Miyamoto, Y. Honda, and Y. Ogura. Sustained release of cis-hydroxyproline in the treatment of experimental proliferative vitreoretinopathy in rabbits. Graefe Arch. Clin. Exp. Ophthalmol. (Albrecht von Graefes Arch. Klin. Exp. Ophthalmol.). 240:672-678 (2002).

211. N. R. Beeley, J. M. Stewart, R. Tano, L. R. Lawin, R. A Chappa, G. Qiu, A. B. Anderson, E. de Juan, and S. E. Varner. 
Development, implantation, in vivo elution, and retrieval of a biocompatible, sustained release subretinal drug delivery system. J. Biomed. Materi. Res. 76:690-698 (2006) doi:10.1002/jbm. a.30567.

212. G. J. Jaffe, C. H. Yang, H. Guo, J. P. Denny, C. Lima, and P. Ashton. Safety and pharmacokinetics of an intraocular fluocinolone acetonide sustained delivery device. Investig. Ophthalmol. Vis. Sci. 41:3569-3575 (2000).

213. F. Kagaya, T. Usui, K. Kamiya, Y. Ishii, S. Tanaka, S. Amano, and T. Oshika. Intraocular dexamethasone delivery system for corneal transplantation in an animal model. Cornea. 21:200-202 (2002) doi:10.1097/00003226-200203000-00015.

214. Y. Wang, P. Challa, D. L. Epstein, and F. Yuan. Controlled release of ethacrynic acid from poly(lactide-co-glycolide) films for glaucoma treatment. Biomaterials. 25:4279-4285 (2004) doi:10.1016/j.biomaterials.2003.10.075.

215. J. T. Theng, S. E. Ti, L. Zhou, K. W. Lam, S. P. Chee, and D. Tan. Pharmacokinetic and toxicity study of an intraocular cyclosporine DDS in the anterior segment of rabbit eyes. Investig. Ophthalmol. Vis. Sci. 44:4895-4899 (2003) doi:10.1167/iovs.02-1112.

216. A. C. Wadood, A. M. Armbrecht, P. A. Aspinall, and B. Dhillon. Safety and efficacy of a dexamethasone anterior segment drug delivery system in patients after phacoemulsification. J. Cataract Refract. Surg. 30:761-768 (2004) doi:10.1016/ j.jcrs.2003.08.028.

217. S. K. Pandey, B. Cochener, D. J. Apple, J. Colin, L. Werner, R. Bougaran, R. H. Trivedi, T. A. Macky, and A. M. Izak. Intracapsular ring sustained 5-fluorouracil delivery system for the prevention of posterior capsule opacification in rabbits: a histological study. J. Cataract Refract. Surg. 28:139-148 (2002) doi:10.1016/S0886-3350(01)01069-0.

218. L. Xie, J. Sun, and Z. Yao. Heparin drug delivery system for prevention of posterior capsular opacification in rabbit eyes. Graefe Arch. Clin. Exp. Ophthalmol. (Albrecht von Graefes Arch. Klin. Exp. Ophthalmol.). 241:309-313 (2003).

219. Y. Sultana, M. Aqil, and A. Ali. Ion-activated, gelrite-based in situ ophthalmic gels of pefloxacin mesylate: comparison with conventional eye drops. Drug Deliv. 13:215-219 (2006) doi:10.1080/10717540500309164.

220. Z. Liu, J. Li, S. Nie, H. Liu, P. Ding, and W. Pan. Study of an alginate/HPMC-based in situ gelling ophthalmic delivery system for gatifloxacin. Int J. Pharm. 315:12-17 (2006) doi:10.1016/j. ijpharm.2006.01.029.

221. J. Balasubramaniam, S. Kant, and J. K. Pandit. In vitro and in vivo evaluation of the Gelrite gellan gum-based ocular delivery system for indomethacin. Acta pharmaceutica (Zagreb, Croatia). 53:251-261 (2003).

222. J. Balasubramaniamand, and J. K. Pandit. Ion-activated in situ gelling systems for sustained ophthalmic delivery of ciprofloxacin hydrochloride. Drug Deliv. 10:185-191 (2003) doi:10.1080/ 713840402

223. Z. Liu, X. G. Yang, X. Li, W. Pan, and J. Li. Study on the ocular pharmacokinetics of ion-activated in situ gelling ophthalmic delivery system for gatifloxacin by microdialysis. Drug Dev. Ind. Pharm. 33:1327-1331 (2007) doi:10.1080/03639040701397241.

224. M. D. Nelson, J. D. Bartlett, D. Corliss, T. Karkkainen, and M. Voce. Ocular tolerability of timolol in gelrite in young glaucoma patients. J. Am. Optom. Assoc. 67:659-663 (1996).

225. B. Srividya, R.M. Cardoza, and P.D. Amin. Sustained ophthalmic delivery of ofloxacin from a $\mathrm{pH}$ triggered in situ gelling system. J. Control Release. 73:205-211 (2001) doi:10.1016/S01683659(01)00279-6.

226. C. Wu, H. Qi, W. Chen, C. Huang, C. Su, W. Li, and S. Hou. Preparation and evaluation of a carbopol/HPMC-based in situ gelling ophthalmic system for puerarin. Yakugaku Zasshi. 127:183-191 (2007) doi:10.1248/yakushi.127.183.

227. H. Qi, W. Chen, C. Huang, L. Li, C. Chen, W. Li, and C. Wu. Development of a poloxamer analogs/carbopol-based in situ gelling and mucoadhesive ophthalmic delivery system for puerarin. Int. J. Pharm. 337:178-187 (2007) doi:10.1016/j. ijpharm.2006.12.038.

228. J. J. Zhang, L. K. Xie, N. M. Zhao, Z. J. Chen, and Y. Xu. Pharmacokinetics of topically applied in-situ-forming gels of fluconazole in rabbit eyes. Yao хие хие bao (Acta Pharmaceutica Sinica). 35:835-838 (2000).
229. J.J. Zhang, C.F. Gao, L.Y. Wang. Ocular pharmacokinetics and bioavailability of $0.2 \%$ ganciclovir in-situ gelling eye drops Zhonghua Yan Ke Za Zhi. 42:637-641 (2006).

230. Y. Cao, C. Zhang, W. Shen, Z. Cheng, L. L. Yu, and Q. Ping. Poly(N-isopropylacrylamide)-chitosan as thermosensitive in situ gel-forming system for ocular drug delivery. J. Control Release. 120:186-194 (2007) doi:10.1016/j.jconrel.2007.05.009.

231. H. R. Lin, K. C. Sung, and W. J. Vong. In situ gelling of alginate/ pluronic solutions for ophthalmic delivery of pilocarpine. Biomacromolecules. 5:2358-2365 (2004) doi:10.1021/bm0496965.

232. H. Gupta, S. Jain, R. Mathur, P. Mishra, A.K. Mishra, and T Velpandian. Sustained ocular drug delivery from a temperature and $\mathrm{pH}$ triggered novel in situ gel system. Drug Deliv. 14:507515 (2007) doi:10.1080/10717540701606426.

233. W. D. Ma, H. Xu, C. Wang, S. F. Nie, and W. S. Pan. Pluronic F127-g-poly(acrylic acid) copolymers as in situ gelling vehicle for ophthalmic drug delivery system. Int. J. Pharm. 350:247-256 (2008) doi:10.1016/j.ijpharm.2007.09.005.

234. G. S. Robinson, E. A. Pierce, S. L. Rook, E. Foley, R. Webb, and L. E. Smith. Oligodeoxynucleotides inhibit retinal neovascularization in a murine model of proliferative retinopathy. Proc. Natl. Acad. Sci. U. S. A. 93:4851-4856 (1996) doi:10.1073/ pnas.93.10.4851.

235. K. L. Garrett, W. Y. Shen, and P. E. Rakoczy. In vivo use of oligonucleotides to inhibit choroidal neovascularisation in the eye. J. Gene Med. 3:373-383 (2001) doi:10.1002/jgm.197.

236. C. Hecquet, G. Lefevre, M. Valtink, K. Engelmann, and F. Mascarelli. Activation and role of MAP kinase-dependent pathways in retinal pigment epithelial cells: ERK and RPE cell proliferation. Investig. Ophthalmol. Vis. Sci. 43:3091-3098 (2002).

237. J. Ruckman, L.S. Green, J. Beeson, S. Waugh, W. L. Gillette, D. D. Henninger, L. Claesson-Welsh, and N. Janjic. 2'-Fluoropyrimidine RNA-based aptamers to the 165-amino acid form of vascular endothelial growth factor (VEGF165). Inhibition of receptor binding and VEGF-induced vascular permeability through interactions requiring the exon 7-encoded domain. $J$. Biol. Chem. 273:20556-20567 (1998) doi:10.1074/ jbc.273.32.20556.

238. S. J. Reich, J. Fosnot, A. Kuroki, W. Tang, X. Yang, A. M. Maguire, J. Bennett, and M. J. Tolentino. Small interfering RNA (siRNA) targeting VEGF effectively inhibits ocular neovascularization in a mouse model. Mol. Vis. 9:210-216 (2003).

239. M. Murata, T. Takanami, S. Shimizu, Y. Kubota, S. Horiuchi, W. Habano, J. X. Ma, and S. Sato. Inhibition of ocular angiogenesis by diced small interfering RNAs (siRNAs) specific to vascular endothelial growth factor (VEGF). Curr. Eye Res. 31:171-180 (2006) doi:10.1080/02713680500514636.

240. M. F. Cordeiro, A. Mead, R. R. Ali, R. A. Alexander, S. Murray, C. Chen, C. York-Defalco, N. M. Dean, G. S. Schultz, and P. T. Khaw. Novel antisense oligonucleotides targeting TGF-beta inhibit in vivo scarring and improve surgical outcome. Gene Therapy. 10:59-71 (2003) doi:10.1038/sj.gt.3301865.

241. T. G. McCauley, J. C. Kurz, P. G. Merlino, S. D. Lewis, M. Gilbert, D. M. Epstein, and H. N. Marsh. Pharmacologic and pharmacokinetic assessment of anti-TGFbeta2 aptamers in rabbit plasma and aqueous humor. Pharm. Res. 23:303-311 (2006) doi:10.1007/s11095-005-9305-2.

242. I. Kitajima, K. Unoki, and I. Maruyama. Phosphorothioate oligodeoxynucleotides inhibit basic fibroblast growth factorinduced angiogenesis in vitro and in vivo. Antisense Nucleic Acid Drug Dev. 9:233-239 (1999).

243. S. Roy, K. Zhang, T. Roth, S. Vinogradov, R.S. Kao, and A. Kabanov. Reduction of fibronectin expression by intravitreal administration of antisense oligonucleotides. Nat. Biotechnol. 17:476-479 (1999) doi:10.1038/8654.

244. M. Kulka, C. C. Smith, L. Aurelian, R. Fishelevich, K. Meade, P. Miller, and P. O. Ts'o. Site specificity of the inhibitory effects of oligo(nucleoside methylphosphonate)s complementary to the acceptor splice junction of herpes simplex virus type 1 immediate early mRNA 4. Proc. Natl. Acad. Sci. U. S. A. 86:6868-6872 (1989) doi:10.1073/pnas.86.18.6868.

245. M. Kulka, C. C. Smith, J. Levis, R. Fishelevich, J. C. Hunter, C. D. Cushman, P. S. Miller, P. O. Ts'o, and L. Aurelian. 
Synergistic antiviral activities of oligonucleoside methylphosphonates complementary to herpes simplex virus type 1 immediate-early mRNAs 4, 5, and 1. Antimicrob. Agents Chemother 38:675-680 (1994).

246. J. M. Kean, S. A. Kipp, P. S. Miller, M. Kulka, and L. Aurelian. Inhibition of herpes simplex virus replication by antisense oligo2'-O-methylribonucleoside methylphosphonates. Biochemistry. 34:14617-14620 (1995) doi:10.1021/bi00045a001.

247. A. Peyman, M. Helsberg, G. Kretzschmar, M. Mag, S. Grabley, and E. Uhlmann. Inhibition of viral growth by antisense oligonucleotides directed against the IE110 and the UL30 mRNA of herpes simplex virus type-1. Biol. Chem. HoppeSeyler. 376:195-198 (1995).

248. K. P. Anderson, M. C. Fox, V. Brown-Driver, M. J. Martin, and R. F. Azad. Inhibition of human cytomegalovirus immediate- early gene expression by an antisense oligonucleotide complementary to immediate-early RNA. Antimicrob. Agents Chemother. 40:2004-2011 (1996).

249. S. P. Henry, R. C. Miner, W. L. Drew, J. Fitchett, C. YorkDefalco, L. M. Rapp, and A. A. Levin. Antiviral activity and ocular kinetics of antisense oligonucleotides designed to inhibit CMV replication. Invest. Ophthalmol. Vis. Sci. 42:2646-2651 (2001).

250. B. Detrick, C. N. Nagineni, L. R. Grillone, K. P. Anderson, S. P. Henry, and J. J. Hooks. Inhibition of human cytomegalovirus replication in a human retinal epithelial cell model by antisense oligonucleotides. Invest. Ophthalmol. Vis. Sci. 42:163-169 (2001).

251. S. K. Sahoo, F. Dilnawaz, S. Krishnakumar. Nanotechnology in ocular drug delivery. Drug Discov Today. 13:144-151 (2008). 